$$
D O E / G 0 / 10562 \ldots F
$$

FINAL REPORT

$$
\begin{aligned}
& \text { c 分 } \\
& v=\text { m } \\
& \text { 二 要竕 }
\end{aligned}
$$

\title{
TECHNOLOGY TRANSFER FOR NEWLY DEVELOPED SENSORS
}

\author{
DE-FC 36 -93CH 10562
}

SUBMITTED BY

ROBERT A. BAREISS

BAREISS ASSOCIATES

MARCH 1,1998 


\section{DISCLAIMER}

This report was prepared as an account of work sponsored by an agency of the United States Government. Neither the United States Government nor any agency thereof, nor any of their employees, make any warranty, express or implied, or assumes any legal liability or responsibility for the accuracy, completeness, or usefulness of any information, apparatus, product, or process disclosed, or represents that its use would not infringe privately owned rights. Reference herein to any specific commercial product, process, or service by trade name, trademark, manufacturer, or otherwise does not necessarily constitute or imply its endorsement, recommendation, or favoring by the United States Government or any agency thereof. The views and opinions of authors expressed herein do not necessarily state or reflect those of the United States Government or any agency thereof. 


\section{DISCLAIMER}

Portions of this document may be illegible in electronic image products. Images are produced from the best available original document. 


\section{INTRODUCTION}

The objective of this contract is to obtain better utilization of sensor technology developed under DOE sponsorship for the pulp and paper industry.

It was thought that a barrier to utilization of these technologies was the unfamiliarity with the industry on the part of the technology developers, and that this barrier might be lowered through the participation of someone intimately familiar with the industry who could arrange contacts and appropriate trials for selected technologies.

The project design consisted of six tasks as described in Appendix $D$ of the contract (see Appendix of this report). Later in the contract period as the AGENDA 2020 compact between the DOE and the paper industry came into being other tasks were added to the contract. These included: 1) defining the industry's priority needs for sensors and controls; 2) providing consultation to the DOE labs as they began to work on selected projects; 3 ) arranging presentations at paper industry technical conferences of key technologies in sensors and controls developed under the Agenda 2020 program.

A final task was added to prepare an overview of the Forest Products industry needs in sensors and controls for a meeting at the National Academy of Sciences sponsored by the DOE. At this meeting the Industries of the Future presented their needs with a view towards determining if there might be any commonality of needs that could be met by focused research.

\section{Results}

Task 1. Review of Sensor Projects

At an initial meeting at DOE headquarters in Washington, a list of nine potential candidates was prepared and the current status of each was reported, (see Appendix). A letter was sent to each of these companies requesting further information (see representative letter to Ciencia Corporation in the Appendix). 
Task 2. Selecting Sensors

On the basis of these reviews, active participation with the following was undertaken, with the results indicated in each instance.

Optra, Inc.

Optra was the first sensor selected because the firm had installed the technology in other industries and did have some preliminary data from a laboratory trial in the paper industry. The application pursued for the paper industry was the measurement of the velocity of the jet exiting from the slice of a paper machine headbox. This is a needed measurement in the industry for improved control of the papermaking process. Two opportunities were secured for mill trials for this purpose, one was at a James River mill in Pennington, Al, and the second was International Paper at their Erie, PA Research Center. In both cases Optra chose not to proceed because they did not have the financial resources needed for sensor modifications and the costs of conducting the trials. This was the first indication that familiarity with the paper industry was not the sole barrier to successful technology transfer.

\section{SPARKTECH}

It was found that this technology had not progressed beyond being a laboratory curiosity.

Spectral Sciences

This firm recognized that some redesign of the sensor technology was necessary and they were seeking funding for that purpose.

Photonic Sensor Systems

This company also required financial assistance for further modifications of their technology. They were able to find this support in other industries. 
Ciencia Incorporated

This technology looked quite impressive. An attempt was made to get Babcock and Wilcox (see below) to consider this approach to measuring lignin content in pulp streams to no avail. Later Ciencia was advised of the Agenda 2020 program in order that they might consider submitting a proposal. They were also given the name of a Professor at a pulp and paper school who could collaborate with them.

Advanced Fuel Research

This firm had well developed technology and some good test results from overseas. On several occasions phone calls were made to Georgia Pacific Corporation at their Corporate headquarters in Atlanta to see if their mill at Woodland, ME was still interested in pursuing this technology.

University of Florida

This University had a DOE contract for laboratory development and mill evaluation of black liquor viscosity sensors. Their pilot plant work was extensively reviewed and assistance was provided in arranging mill trials.

Originally the Chesapeake Corporation mill in West Point, VA had been an active participant in this project. When it came time to install a sensor for evaluation they exhibited some reticence to proceeding. Contact was made with the Vice President for Manufacturing Technology to obtain his help in keeping this on track.

\section{Babcock and Wilcox R\&D Division}

Several meetings were held with this firm and their Commercialization partner, Bailey Controls. They were advised of the technology for making this measurement developed by Ciencia and its apparent superiority. They chose not to follow up on this advice. As they were not receptive to this and other advice provided to improve likelihood of success for this project, DOE eventually canceled their contract. 
Institute of Paper Science and Technology

IPST, in cooperation with ABB, was successful in obtaining DOE funding for a full scale mill trial of this technology. Assistance was provided during the contracting phase. Another supplier objected to the proposed contract, making the claim that they had a commercial product available to make this measurement. Through industry contacts it was shown that this claim was premature and the contract was awarded.

Several meetings were held with ABB and IPST in planning for these trials and in consultations on mill locations for conducting the trials. The trials of this sensor are being conducted at the Herty Foundation in Savannah, GA, and at the Georgia-Pacific mill in Cedar Springs, GA.

Task 3. Sensor Demonstrations

It will be seen from the above that the only demonstrations that occurred were those funded by direct contracts between the sensor supplier and the DOE.

Task 4. Monitoring the Demonstrations.

Only two of these sensors resulted in mill demonstrations: the viscosity sensor by University of Florida, and the ultrasonic on-line paper web sensor by the Institute of Paper Science and Technology. In the first instance the demonstrations did not get underway before the termination of this contract. In the second instance, the demonstrations have not yet begun.

Task 5. Demonstration Reports.

The two demonstrations are under direct contract with the DOE and will be reported by the supplier under the terms of their contracts.

Task 6.

Monthly Progress reports were submitted to DOE and this final report completes the reporting requirements. 
Additional Tasks (AGENDA 2020).

At the beginning of the AGENDA 2020 program this contractor was invited to be a member of the Sensors and Control Task Group of AF\&PA. After this Group had developed a priority list of Sensor and Control needs for the industry, this contractor led the preparation of a document which described these needs in some detail. This document was circulated to the National Labs to assist them in preparing proposals for submission. On numerous occasions specific advice was supplied to the labs in response to their questions.

This contractor took the initiative to present an overview of the Agenda 2020 program to a meeting of the Paper Sensors Committee of the Process Control, Electrical and Information Division of the Technical Association of the Pulp and Paper Industry. This was well received resulting in an invitation to arrange a technical session at a subsequent Conference of TAPPI. This session was held at the joint meeting of the Engineering and Papermakers Divisions of TAPPI held in Nashville on October 8,1997. The program outline and speakers are shown in the Appendix. This program was well received. There were 54 people in attendance and numerous requests were received for copies of the presentations.

When the DOE contracted with the National Academy of Sciences to undertake a program in cross-cutting sensor development for the Industries of the Future this contractor provided a technical paper on the needs of the Forest Products industry.

\section{Conclusions.}

It should be noted that the OPTRA, Spectral Sciences, Photonic and Ciencia Sensors were all SBIR projects which assume that the contractor will devote the funds and time necessary for Phase III Commercialization. DOE does offer assistance in this Phase through the Dawnbreaker program but no funding.

The two projects that are going forward to in-mill demonstration are funded projects including the cost of in-mill work. 
It is clear; 1) that industry contact is a barrier to acceptance of technology developed by DOE, 2) that another barrier, i.e. funds to implement demonstrations is another significant barrier, and 3) that a conclusion reached in an Industry Profiles report ${ }^{1}$ is also correct.

"In terms of implementation, it is generally perceived in the industry to be too risky to be the first mill to install a new process or technology. As a rule of thumb, three successful commercialized cases of a new technology are required before the industry will fully adopt that technology."

Recommendations.

The SBIR program assumes that contractors will carry through on in-mill demonstrations. DOE might review awardees' past performance in this regard in the future and make this a criteria for new awards. DOE might also review the outcome of SBIR projects more closely and consider funding demonstrations where it is deemed likely that benefit will be realized and can be obtained. This has been done in the past and could be accomplished through the Agenda 2020 program.

1. Industry Profiles, Final Report Paper DE-AC01-87CE40762 


\section{APPENDIX}

1. Scope of Work

2.List of Sensors

3.Letter to Participants

4.Agenda 2020 Technical Session

5. Agenda 2020 Sensors and Control Needs

6. Sensor and Control Needs for the Forest Products Industry. National Academy of Sciences. 
FOREST PRODUCTS INDUSTRY

AN OVERVIEW OF NEEDS IN PROCESS CONTROL

\author{
Robert A. Bareiss \\ Bareiss Associates \\ NATIONAL RESEARCH COUNCIL \\ Panel on Manufacturing Process Controls \\ October 22, 1996 \\ Washington, DC
}




\section{MEASUREMENT AND CONTROL NEEDS \\ OF THE FOREST INDUSTRIES}

Robert A. Bareiss

Bareiss Associates

\section{THE FOREST INDUSTRY}

The Forest Industry harvests trees and converts them into wood and paper products. In both product lines it is important to obtain the highest yield from the raw material and to convert it, wherever possible, into the highest value end products.

Our raw material is a renewable resource and the industry is dedicated to a sustainable growth agenda. In the past year the industry planted 1.3 billion trees in support of this agenda.

The simple block diagram of Figure 1 outlines the major process areas and the interrelationship between lumber and paper. This interrelationship is important to the goal of maximizing product yield from the starting raw material.

The diagram indicates that the lumber mill and pulp mill are on the same property. This is not generally the case, but the flow of material from the lumber mill to the pulp mill is not geography dependent.

\section{INDUSTRY ASSOCIATIONS}

The forest industry has two Associations which address industry-wide concerns for technology in general and sensors and control in particular.

The American Forest and Paper Association is a Company Association. In 1994 AF\&PA published an Agenda 2020 which is a vision of the research needs of the industry in order to reach a desired state twenty-five years out. Six high priority technology areas were identified as being vital to achieving this vision, Table 1. One of these areas is Sensors and Controls, Table 2. A Task Group was formed to develop a list of priority needs in this area.

Many of the members of this Task Group are also members of AF\&PA's Measurement Technology Committee. This Committee is tasked with evaluating commercially available sensors. 
The Technical Association of the Pulp and Paper Industry members are individuals who are employed in the technology of pulping and papermaking. TAPPI has a Foundation which sponsors research at Colleges and Universities which do not have a paper curriculum. This Foundation periodically convenes a Workshop to identify Paper Industry Research Needs.

The most recent workshop was held in April 1996. Sensors and Process Controls was one of the eight specific technology areas considered in this workshop. Sixtynine (69) participants with R\&D backgrounds participated in this workshop.

This Workshop identified 67 sensor and control needs in the eight technology areas (Table3). The 69 participants were asked to indicate their opinion of priority using the criteria of benefit to the industry, inadequacy of the current state-of-the art, precompetitive nature of the development work needed, and time frame for development beyond three years. This ranking produced the seven top-priority needs presented in Table 4.

These needs were presented by the AF\&PA Task Group in a recent request for proposals to be funded by DOE/OIT.

\section{WOOD PRODUCTS}

The lumber mill has three product lines: dimension lumber, studs, and plywood. Logs are selected for each line based on their potential to provide the maximum yield and quality. The waste material, slabs and rejects, is converted to chips and sent to the pulp mill. Note that cores from the plywood mill are delivered to the stud mill.

Bark and sawdust can be used as fuel on site to provide energy for lumber drying. The sawdust can in some cases be sent to the pulp mill.

The sawmill has a number of sensor and control applications. Creating square and rectangular lumber cross-sections from logs is essentially squaring the circle. Since the log cross- sections are not necessarily circular, and because the logs have taper over their length, positioning the logs with respect to the saw blades is an important measurement and control application.

The lumber pieces will have defects such as knots. Separating lengths into segments which will segregate the defects is important to the goal of achieving the highest end value products.

Finally, both lumber and plywood must be dried to specification. This is yet another measurement and control application. 


\section{PAPER}

Let us turn our attention now to the paper side. Note that lumber and paper are produced from the same raw material. In the case of lumber the end product must be strong, rigid, and defect free. In the case of paper the end product must be strong, flexible, and defect free.

The structural characteristics of wood which make it rigid are seen in the schematic representation of Figure 2, and the micrograph of Figure 3. Wood is made up of individual fibers which are tightly bound to each other: God's reinforced laminated structure.

In Figure 4 we note that fibers themselves have structure which gives them rigidity as well.

How do we change from this rigid structure to a flexible product? The conversion process has three steps; Separate individual fibers, treat individual fibers, and recombine the fibers.

\section{A. Separation}

There are two main approaches to the separation of individual fibers- mechanical and chemical. In the interest of time this presentation will focus on the chemical approach.

The block diagram of Figure 5 shows the major processes from digester to paper machine, referred to as the fiber line.

It begins with the digester where wood, in chip form, and chemicals are combined under pressure and temperature. The chemicals penetrate the chips and dissolve the lignin which binds the fibers to each other. The next step is to remove the mixture of fibers and spent chemicals from the digester so that they can be separated by washing.

The spent chemicals are sent to a recovery boiler where the organic constituents are combusted, supplying heat for steam generation, and the inorganics fall to the furnace floor as smelt.

The smelt, containing sodium carbonate, is then passed to the recaustizing area where the sodium carbonate is reacted with lime to form sodium hydroxide. The sodium hydroxide is returned to the digester for another cycle.

The processes of recovering heat and spent chemicals are essential to the economic viability of the chemical digesting process. These areas of the mill present some challenges for measurement and control. 
Returning now to the fiber line, the pulp is next passed through a set of screens and cleaners to remove oversized, troublesome, and unwanted particles from good papermaking fibers.

Where white papers are required, the pulp is next bleached. Chlorine compounds have typically been used here. Due to ever increasing environmental concerns processes using oxygen are beginning to emerge.

\section{B, Treatment}

The next process stage for both brown and white pulps is refining. Remember, the fibers have a structure which gives them rigidity. The purpose of refining is to disrupt this structure so that the fibers will become flexible.

Refining is a mechanical process. The fibers are subjected to impacts which disrupt the multi-layer structure allowing the fiber to collapse into a flexible ribbonlike form. After refining the fibers pass through another set of screens and cleaners.

The fibers are now ready to be recombined to make a continuous web of strong and flexible paper.

C. Recombination

Fiber recombination is accomplished on the paper machine. This machine has three main sections- wet end, press, dryer.

At the wet end the fibers are recombined to form a continuous web of paper. Chemicals may be added here, depending upon paper grade, to enhance certain properties.

The press section is next in line. This section may have various configurations of rolls which apply pressure to the web. This pressure consolidates the web structure and removes some of the remaining water.

The dryer section follows. In this section more water is removed by passing the web over a series of steam heated drums where the final moisture level is obtained by evaporation.

The paper is then wound on a reel and prepared for the converting processes which follow. 
I will take you through the process again, this time with more detail describing these seven priority needs. They are presented in process order from fiber raw material to paper machine reel, rather than in priority ranking.

\section{SENSOR/CONTROL NEEDS}

\section{A. Separation}

The vast majority of our needs are for measurements rather than control. The reason for this will become apparent to you in the discussion that follows. In this discussion, I think it might be useful to emphasize a particular property of the final paper product in order to see the interrelationship of the various steps in achieving this property.

For this purpose I have chosen the property of strength. You are all familiar with corrugated containers. These converted paper products along with brown paper bags make up $35 \%$ of all paper made in the U.S.

Corrugated containers are made to a strength specification which is actually printed on the container (Figure 6). These containers are made from two paper webs held apart by a corrugated separator. The outer plys are called linerboard and the corrugated separator is called medium. The linerboard portion is a two ply structure made on the paper machine. The outer ply, called the top liner is made from a stronger fiber than the inner ply, called the base.

These labels indicate a strength for the box, Burst having the units of PSI, and the basis weight, or amount of fiber, in the top liners of the of the two facing webs. In Figure 6, one box has a Burst strength of 200 psi and the basis weight for each face is $42 \mathrm{lb}$ per $1000 \mathrm{sq}$. feet. The other box has a burst strength of $125 \mathrm{psi}$ and the top liner weights are $26 \mathrm{lbs} / 1000 \mathrm{sq}$. $\mathrm{ft}$.

Another picture we need to have in mind as we follow the process of strength development is the typical Gaussian distribution curve, Figure 7. The major problem facing the paper industry is variability. As this figure shows, for the parameter of strength if variability can be reduced then the target value can be lowered without increasing the percent defective. This target shift represents increased profitability.

We begin with the digester. Figure 8 is an instrument and control diagram for a continuous digester. Wood chips and the cooking liquor are introduced at the top of the digester and flow downward in what is assumed to be plug flow. The upper section of the digester is the impregnation zone. Flow rate is such that it takes approximately 60 minutes for the chips to pass through this zone. During this time the cooking chemicals are impregnating the chips. In the Kraft process the active 
cooking chemicals are sodium hydroxide $(\mathrm{NaOH})$ and sodium sulfide $\left(\mathrm{Na}_{2} \mathrm{~S}\right)$. The reactions that occur during Kraft pulping are complex and not totally understood.

The chip mass then passes through two cooking zones in sequence. In the upper zone the cooking liquor is continuously circulated through external heaters to maintain temperature at about $140^{\circ} \mathrm{C}$. The time of passage through this zone is approximately 45 minutes. In the lower cooking zone the temperature is elevated to about $165^{\circ} \mathrm{C}$ with a retention time of about $1 \mathrm{Hr}$.

The bottom of the digester is the wash zone where the cooking process is quenched and some washing is accomplished. The chips are removed from the bottom of the digester through a blow valve. The pressure drop across the blow unit serves to disintegrate the chips into pulp. The separation process is completed at this point.

\section{CHIP CHARACTERISTICS}

Two of the priority needs are in the digester area. The first has to do with the wood chips. Moisture content is one important property of the chips due to its effect on liquor concentration. Referring back to the saw mill you will remember that residual material is chipped and sent to the pulp mill. Some of this residual material will be slabs from green wood and others will be reject material following the drying process. In the case of chips from green wood, moisture content will vary. A particular problem with chip moisture measurement occurs in Northern climates during winter months when the chips are frozen.

Chip size and size distribution are important because of the effect on liquor penetration rate. Chips are screened prior to the digester to remove over and under size material, but the accepts still cover a considerable range of sizes.

The identification of Wood Species is also important, particularty as between hardwood and softwood.

Chip density is important because the chips are delivered to the digester on a volumetric basis and cooking chemicals are ratioed to mass.

Finally, chip variables which change due to chip age are important. These parameters include acidity, extractive content, and cellulose degradation. 


\section{PULPING CHEMISTRY}

As you would expect, sensors for pulping chemistry are very important, and it would be desirable to make these measurements in the digester. In Figure 9, you will note that as the delignification process proceeds the wood constituents, hemicellulose and cellulose, are also removed, although to a lesser extent. Note that the yield also decreases, where yield is defined as pounds of fiber produced per ton of wood, and the strength potential of the fibers increases. Measurement of these three constituents; lignin, hemicellulose and cellulose would be highly desirable.

This process can be stopped at any point along this yield curve depending upon the paper grades that are to be made from the pulp. However, due to non-uniform chip size, non-uniform circulation of the cooking chemicals, and departures from plug flow the final product will exhibit considerable variation around any given end point, the Gaussian distribution.

For linerboard the top liner is made to a higher strength specification than the base component. The higher strength is obtained initially by carrying the digesting process to a higher degree of lignin removal.

Measurements of the pulping liquors are also important. Here we are looking for measurements of effective alkali, residual alkali, and total titratable alkali. These terms are defined in Table 5.

Real time measurements of the properties of chips, fibers, and pulping liquors would all contribute to our ability to reduce strength variability.

Control of this process is based primarily on feed forward principles. The time of passage through the digester and the temperatures in the several zones are controlled to meet some time/temperature criteria. At the blow line a sample is taken every hour. This sample is titrated to produce a number called the KAPPA number which is an estimate of the degree of delignification. This sample size is about one quart of product and is taken to be representative of the 60,000 gallons that may have passed through the blow line in an hour. The trend of these hourty values is used for feed back control. 


\section{B. TREATMENT}

\section{Refining}

The next critical measurement need occurs at the refiners. One type of refiner is shown in Figure 10. This is a single rotating disc refiner. The pulp enters the refiner at the center and as it progresses to the periphery the fibers are subjected to impacts as the rotating bars pass the fixed bars. Figure 11 shows the appearance of the fibers before and after refining.

\section{Fiber Properties}

Here we would like to know fiber properties after refining. These properties are listed in Table 6. Most of these properties contribute to the strength of the final paper web.

Some of these measurements can be made in the laboratory on samples withdrawn from the process stream. Obviously these are not continuous real time measurements. The measurement of drainage rate (freeness) can be made more frequently at the refiner on samples drawn automatically from the pulp stream. These measurements are rarely used for feed back control of the process. The most prevalent method of control here is based on a computed parameterHorsepower Days per Ton. This parameter is computed from a measurement of power to the refiner and an estimate of dry fiber flow rate obtained from flow and consistency measurements.

The problem with this measurement is that refining is a triple random process. Not all fibers are impacted, all impacts are not of the same degree, and individual fibers may respond differently to a given impact.

Referring again to Figure 11, note that after refining the flexible ribbon-like structure of the fibers allows them to conform to each other at crossing points which increases the area of contact and enhances bonding and therefore strength. The fibrillation of the outer layers of the fiber adds to the strength of the fiber network.

Earlier in this paper I mentioned mechanical methods for fiber separation. One of these methods is called thermomechanical pulping (TMP). In this process refiners much like those used for pulp refining are employed. The principal difference is that these refiners are pressurized so the temperature can be elevated. Wood chips are introduced into the refiner and both the fiber separation and fiber preparation functions are accomplished. Typically this refining is carried out in several refining stages in series. The same fiber characteristics as defined above are required here. 


\section{Consistency}

The next critical measurement is consistency or the percent solids in the fiber stream. It is important in those parts of the process where control is on the basis of dry fiber content such as refining, chemical addition rate, blending of pulp streams. The Measurement Technology Committee of AF\&PA is currently conducting its second evaluation of commercially available instruments.

\section{RECOMBINATION}

\section{Paper Machine}

We have now completed the separation and treatment steps and are ready to recombine the fibers to make a sheet of paper. This step is accomplished on the paper machine which has three major sections- the wet end, the press section, and the dryer section as shown in the schematic drawing, Figure 12.

At the wet end the consistency of the paper making stock is reduced to less than $1 \%$ and delivered to a headbox. In the headbox the stock is distributed laterally and ejected from the front lower edge in a jet the full width of the machine, Figure 13. The machine width may be as much as $300^{n}$. The jet falls on a moving wire which is supported on a table having a number of devices to aid in removing water. Water removal is by gravity with some vacuum assist.

On the wire, the fibers aggregate (recombine) in flocs and intertwine in a manner to form a continuous web. At this point important characteristics of the web are determined. Two main attributes are floc size and distribution and fiber orientation. At the end of the table the solids content has been increased to about $30 \%$ and the web has sufficient strength that it can be peeled off the wire and passed on to the press section.

\section{Colloidal Charge Measurements}

At the wet end of the papermachine various chemicals are blended with the fibers for the purposes listed in Table 7. The pulp fibers and many of the additives hold colloidal charges. The fiber charge is typically negative or anionic while many of the chemicals hold positive or cationic charges. Upsets in the net surface charge of the pulp delivered to the paper machine can occur quickly and lead to difficulties in papermaking, including low sheet strength, web breaks on the paper machine, and changes in drainage on the wire which can slow down the paper machine. Control of additives at the wet end is currently done without benefit of on-line measurement of colloidal charge measurements. 


\section{Press Section}

The press section applies pressure to the web which serves to consolidate it and remove additional water. Consolidation while the web is still relatively wet is important to the development of final web properties, particularly strength.

As the web passes from one section to the next it is subjected to tension. The degree of tension, called the draw, is also important to strength development.

\section{Dryer Section}

After the press section the web passes through the dryer section. This section consists of a number of drums which are heated internally by steam. The final moisture content of the web is achieved here by evaporation. The steam used here is provided by the recovery boiler. Control of final moisture content is accomplished in the dryer section by control of the steam introduced to the dryer cans.

\section{Paper Machine Reel}

The web is then wound on rolls the full width of the machine. These full width rolls are moved to a slitter/winder which reduces them to rolls having a width and diameter suitable to the final converting process.

A number of quality measurements are made between the dryer section and the reel. The three typical measurements are basis weight (mass per unit area), moisture content and caliper or thickness. These measurements are made by a set of sensors mounted in a sensor carriage which traverses back and forth across the web while the web is moving longitudinally at paper machine speed - 2000 6000 feet per minute. The combination of sensor traverse and paper web motion produces a zigzag track over the paper web, with only a very small portion of the web actually being measured.

Furthermore, for control purposes it is important to separate the machine direction and cross-direction components of variance. Given the skewed track of the sensors on the paper web these components can only be estimated.

\section{6. $100 \%$ Web inspection}

It would be highly desirable to have sensors which can make the required measurements in the true cross direction and at a higher rate so that something approaching $100 \%$ of the web can be measured. At this time several of the DOE National Labs have formed a consortium to solve this problem. 


\section{Printability}

The final sensor requirement in this high priority list is printability. This is a measure of the print quality obtained under normal conditions. It is dependent on the printing method used, Figure 14, and on such sheet characteristics as smoothness, absorbency, moisture content, formation, opacity, brightness, ink receptivity, compressibility, surface energy, and mottle. Suffice it to say that the concept of printability is rather complex.

There is a connection here between wet end chemistry and printability as the property of absorbency can be controlled by the introduction of additives.

A final comment on paper strength is in order here. Printability is an important property to printers because it relates directly to the quality of their final product. Equally important is paper strength. Paper suppliers are rated on a factor called web breaks per 100 rolls. A web break is an interruption in the printing process which causes lost time and therefore contributes directly to the cost of production.

\section{REFERENCES}

Handbook for Pulp and Paper Technologists, G.A. Smook, TAPPI, Atlanta, GA Pulp and Paper Manufacture, D. B. Brewster, TAPPI, Atlanta, GA Agenda 2020, American Forest and Paper Association, Washington, DC Paper Industry Research Needs Workshop, TAPPI, unpublished 


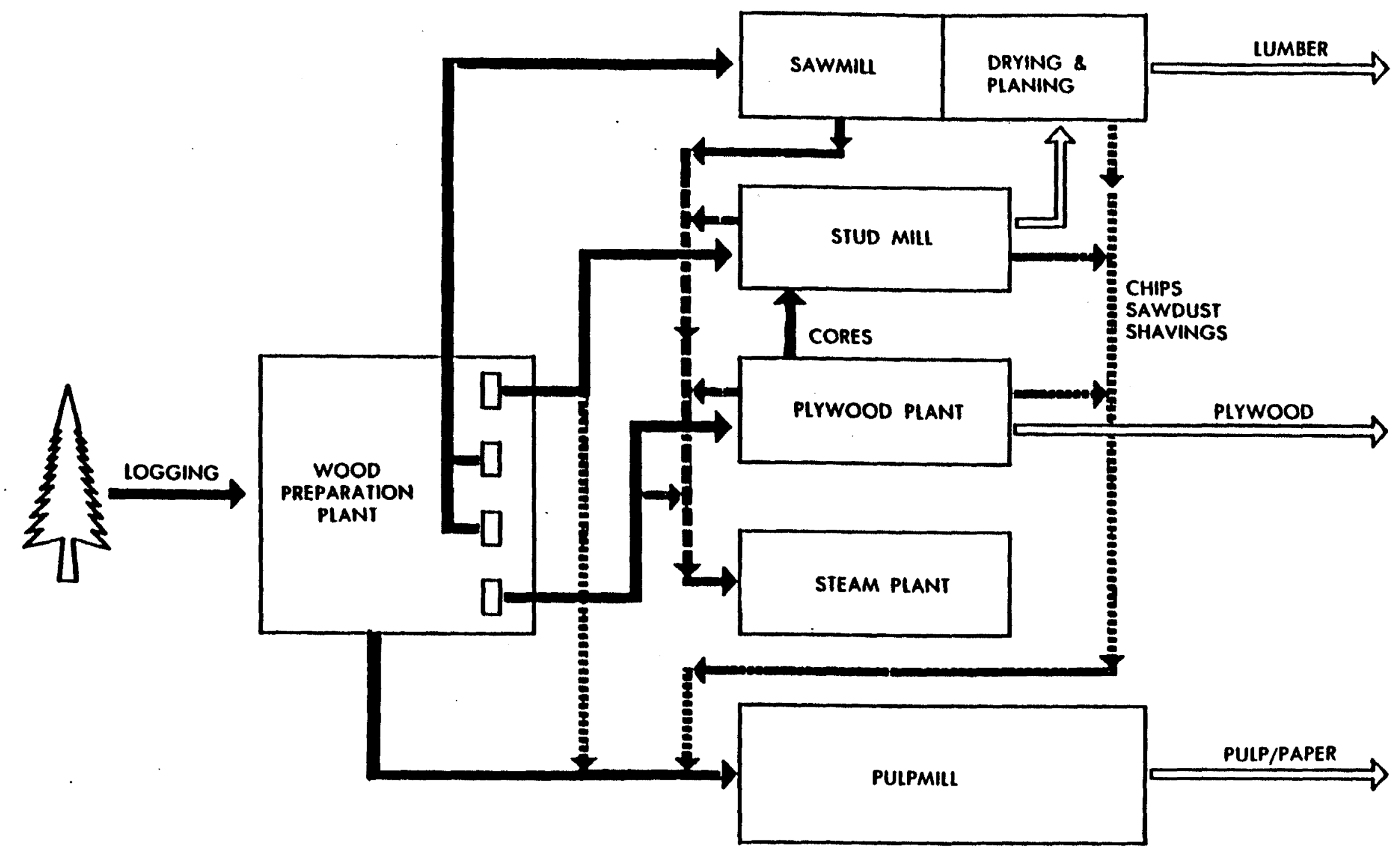

Figure 1 


\section{TRANSVERSE VIEW}

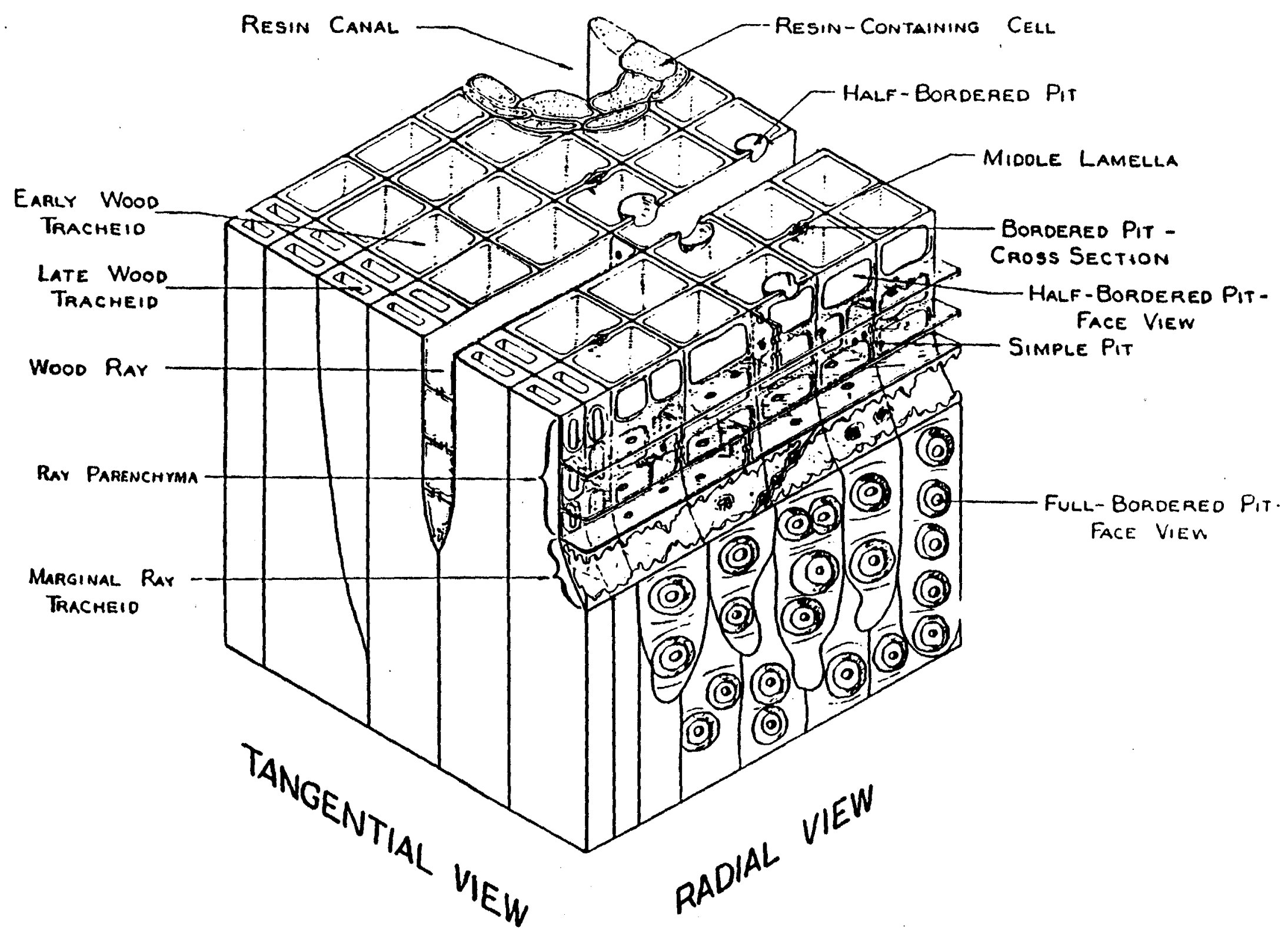

Fig. 2. A fictitious wood block illustrating the structural features of a softwood (Hyland). 


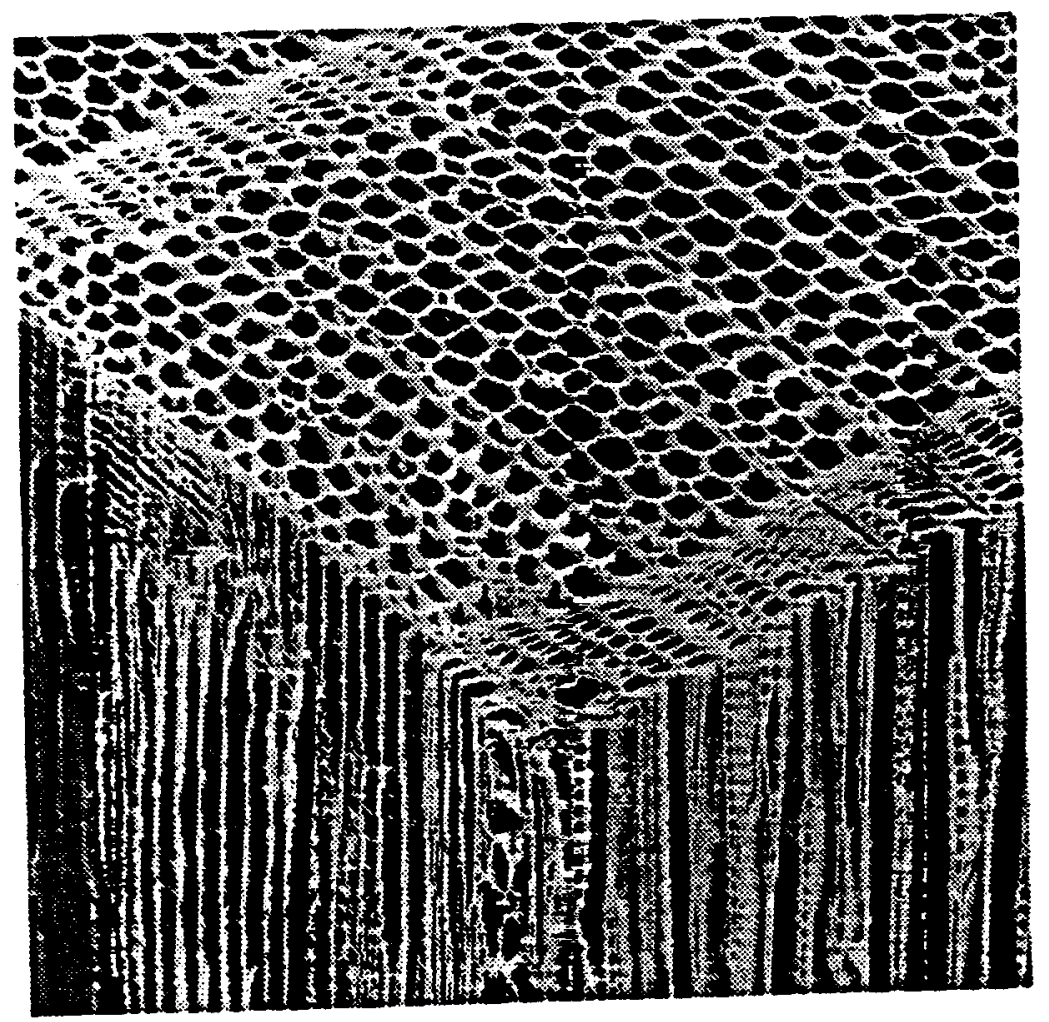

Sitka spruce cube (micrograph courtesy of
Forintek Canada Corp., Westem Laboratory).

Figure 3 


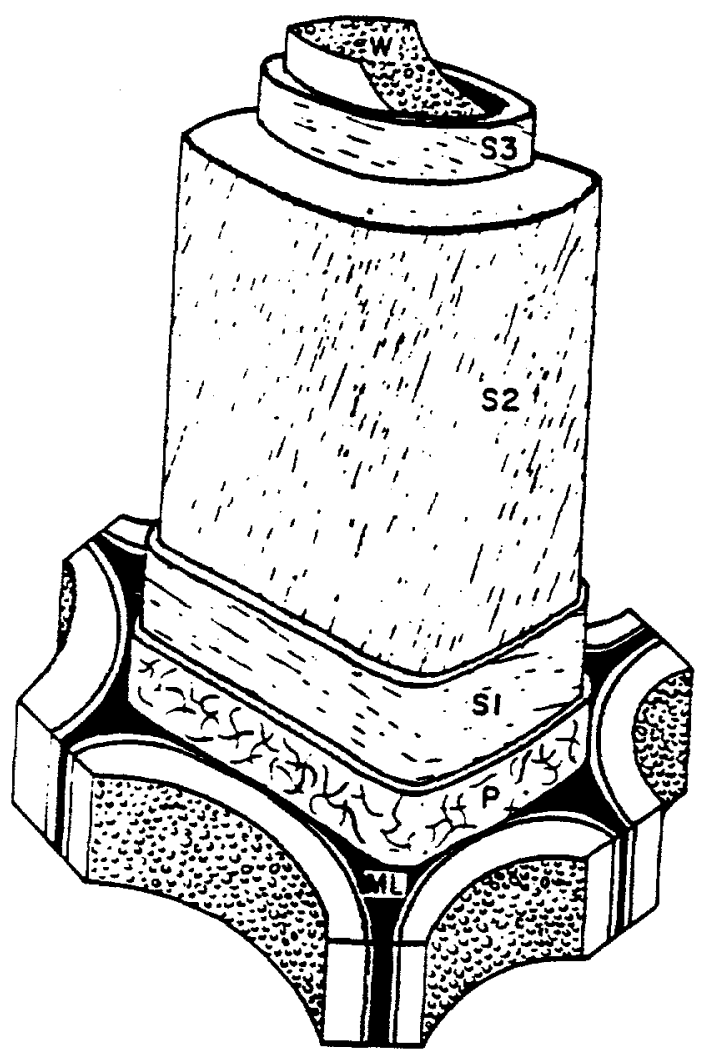

Fig. 2-5. Diagram of cell well organization.

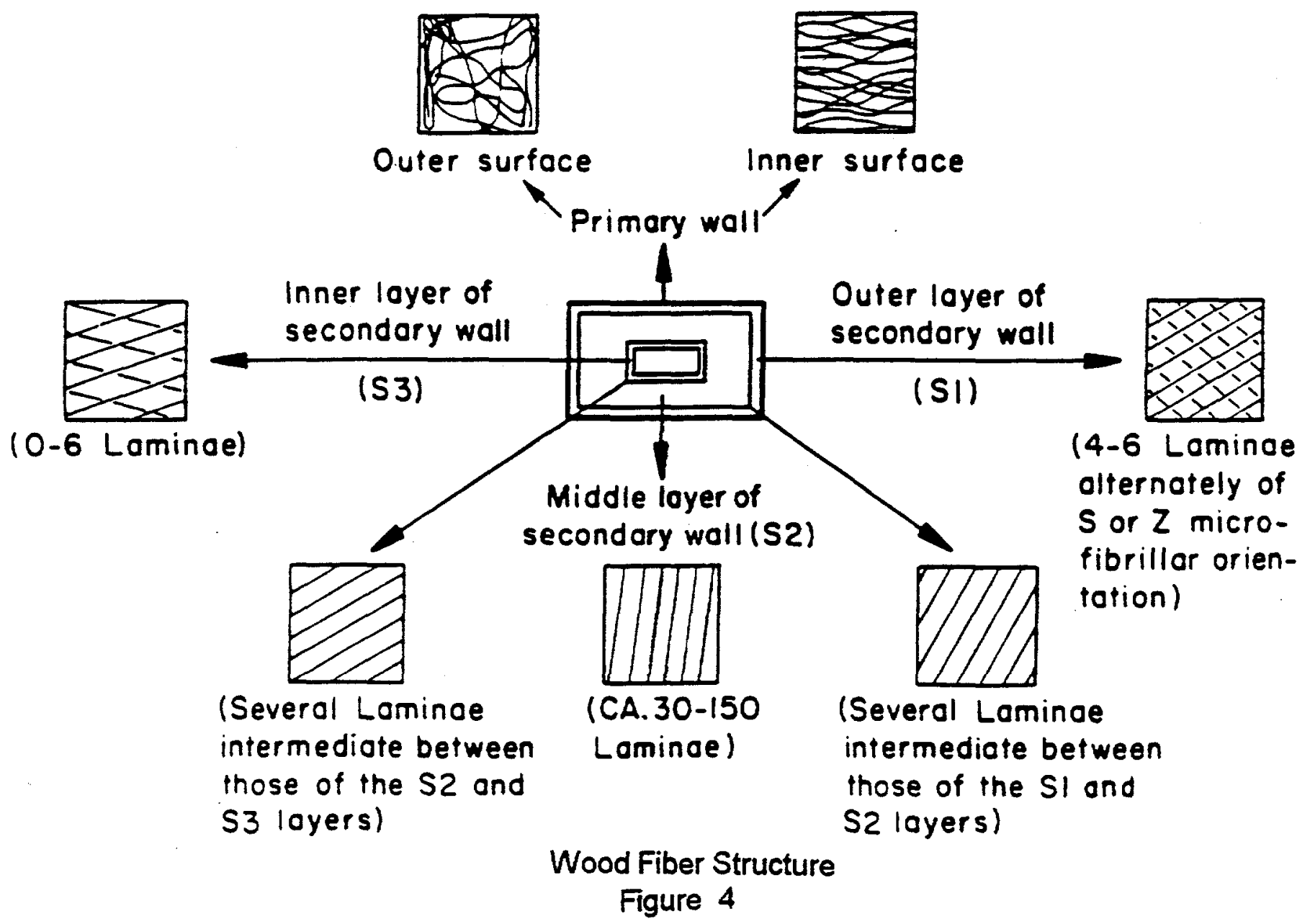




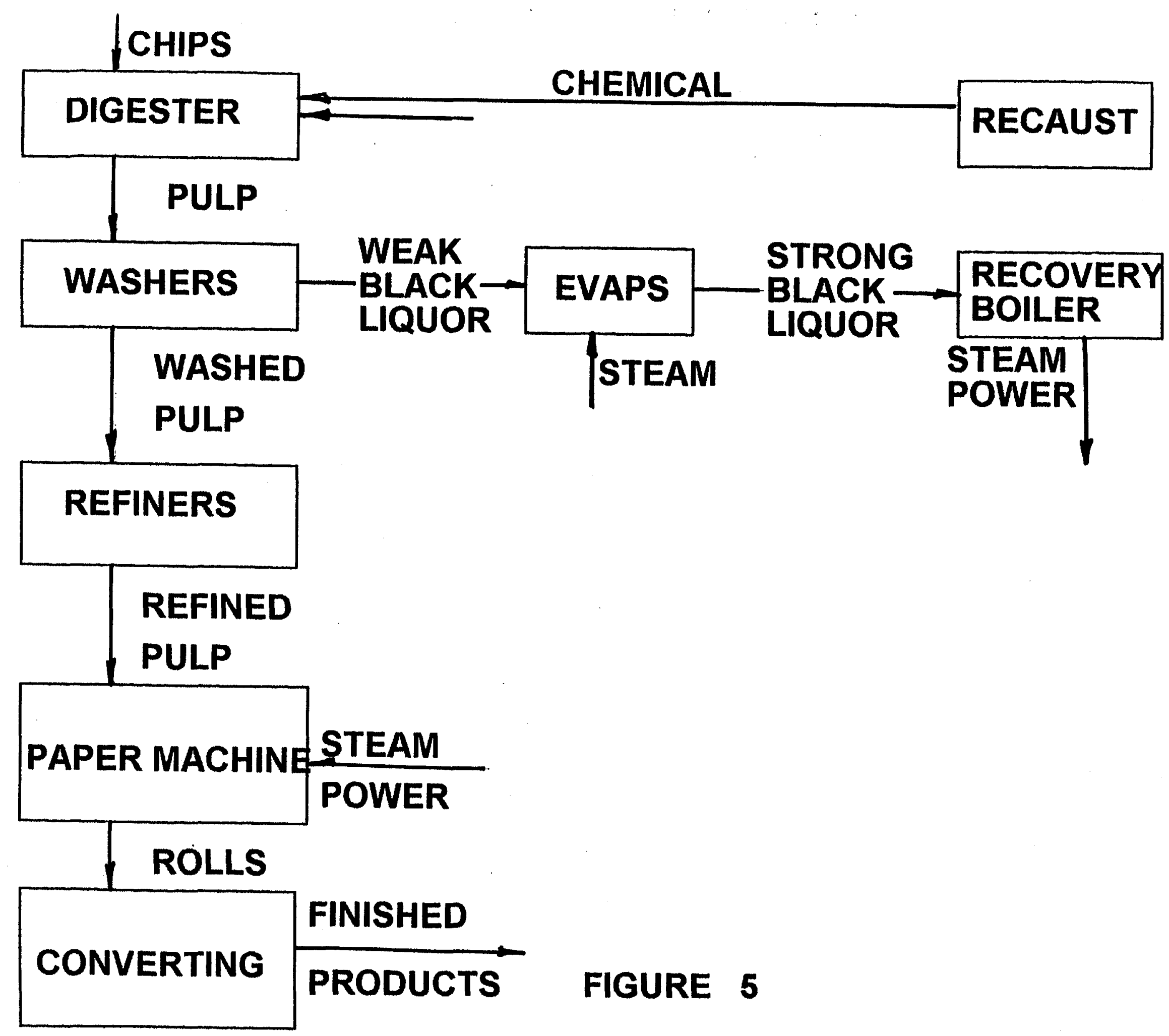




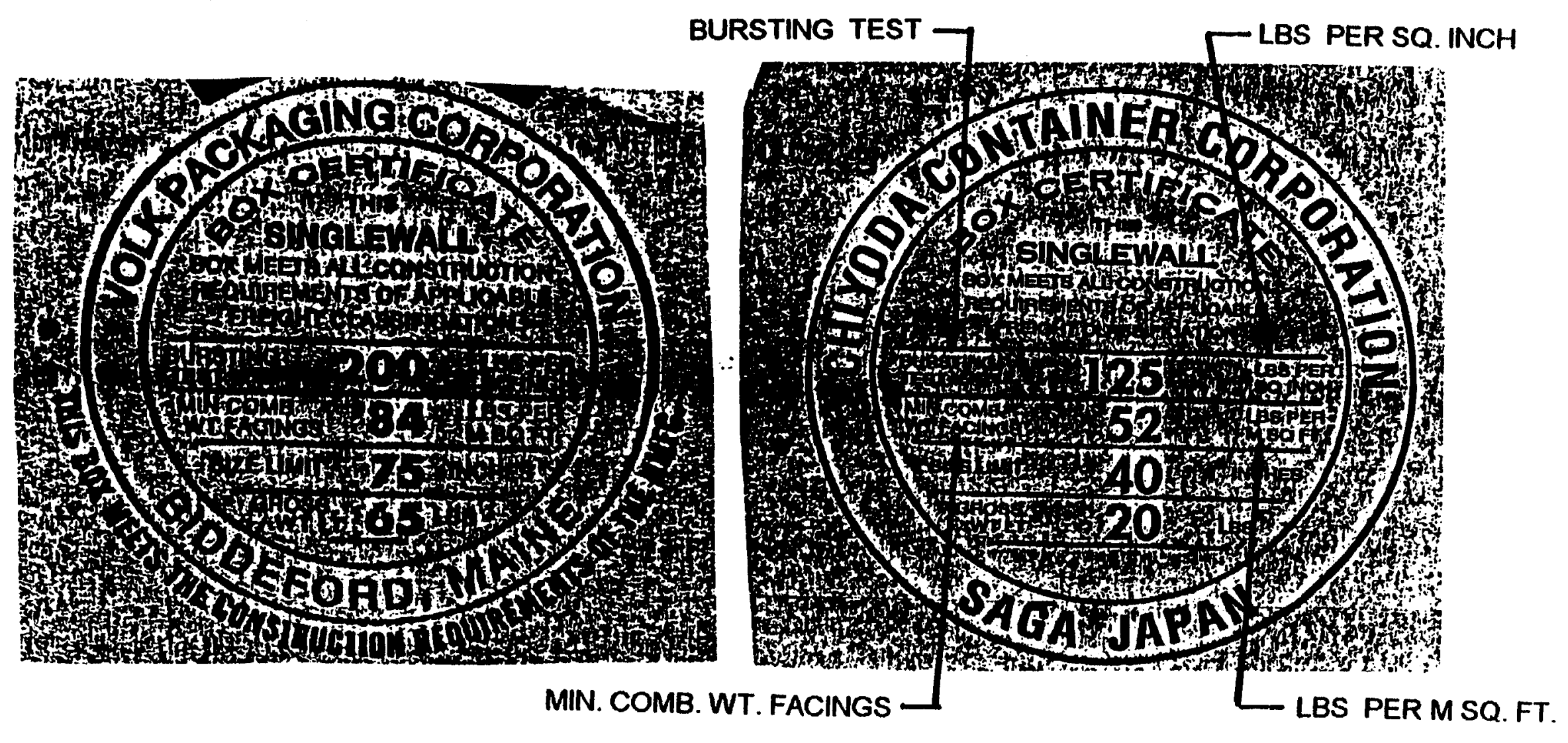

Figure 6 
Reducing strength variation allows average strength to be lowered while maintaining the same failure rate

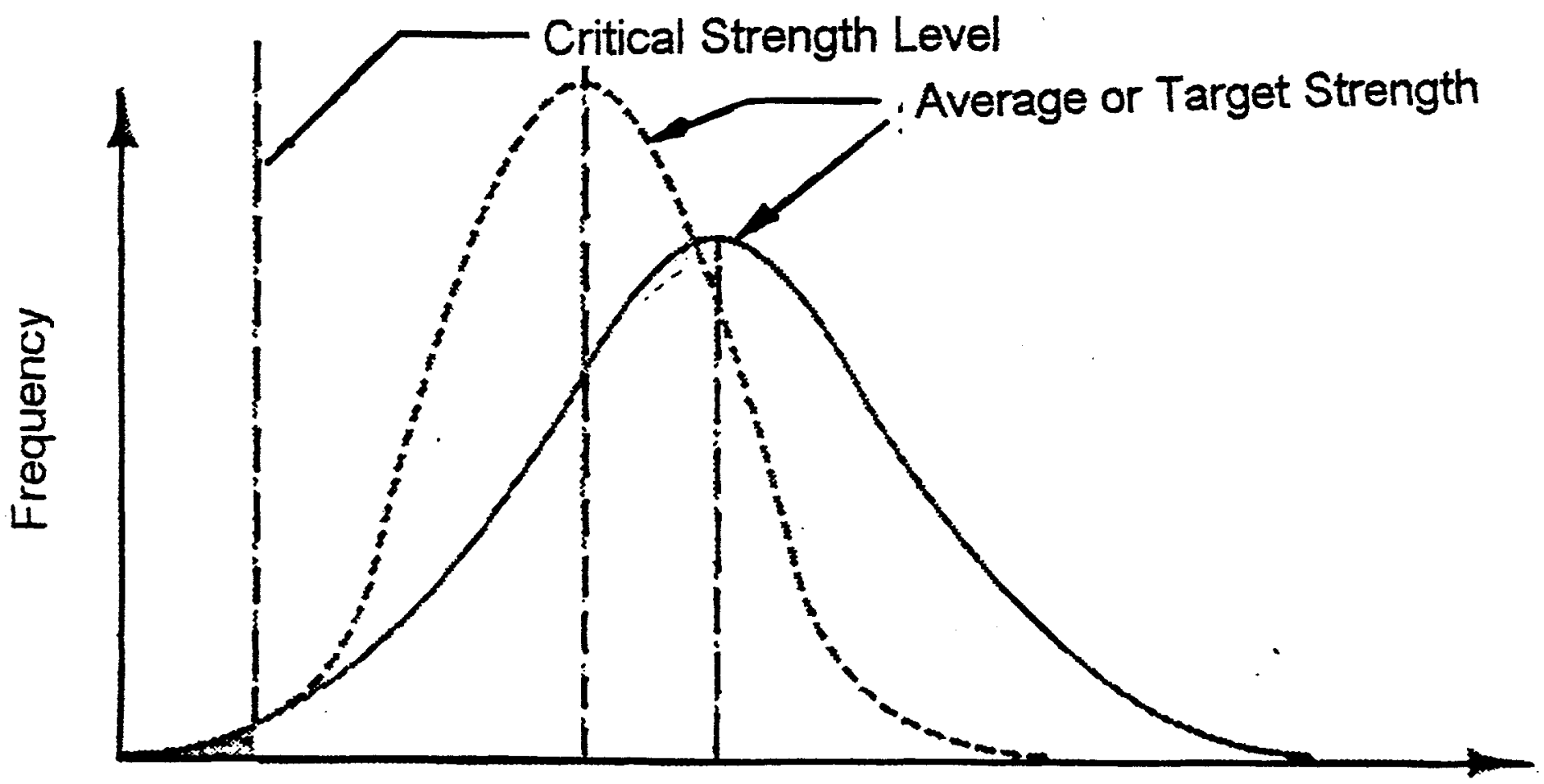

Strength

Figure 7 


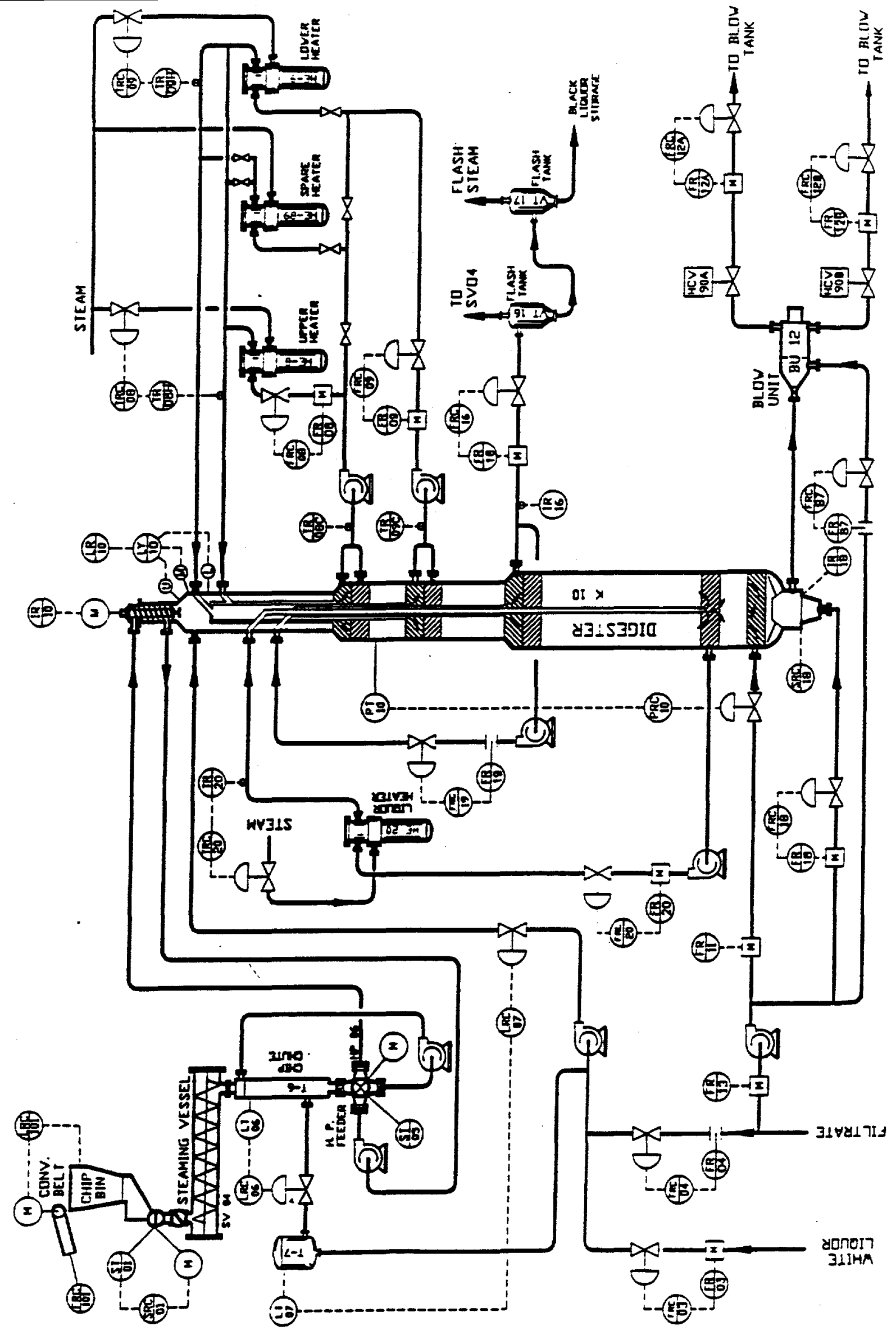

$\infty$
$\frac{0}{3}$
욤 


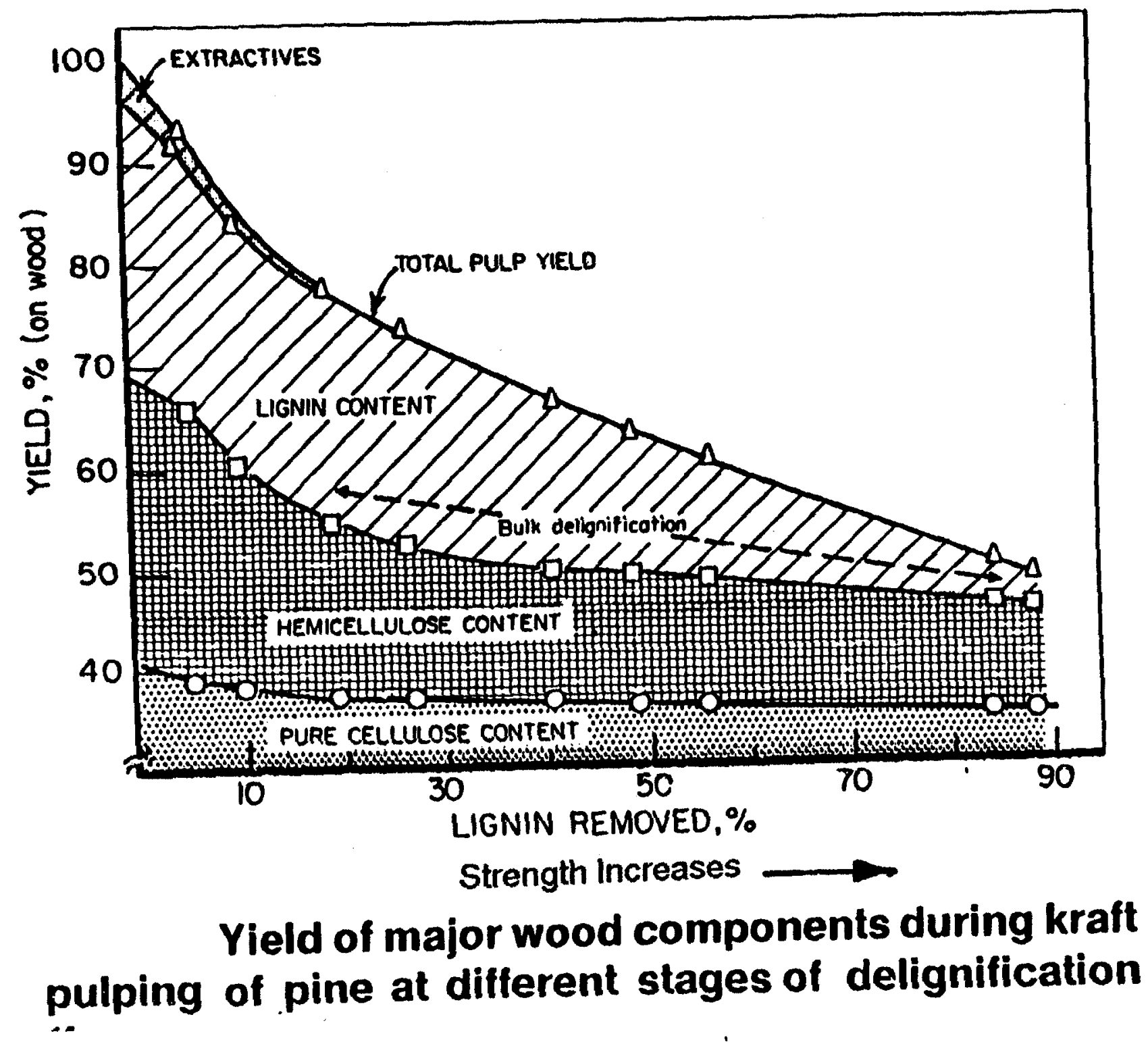

Figure 9 

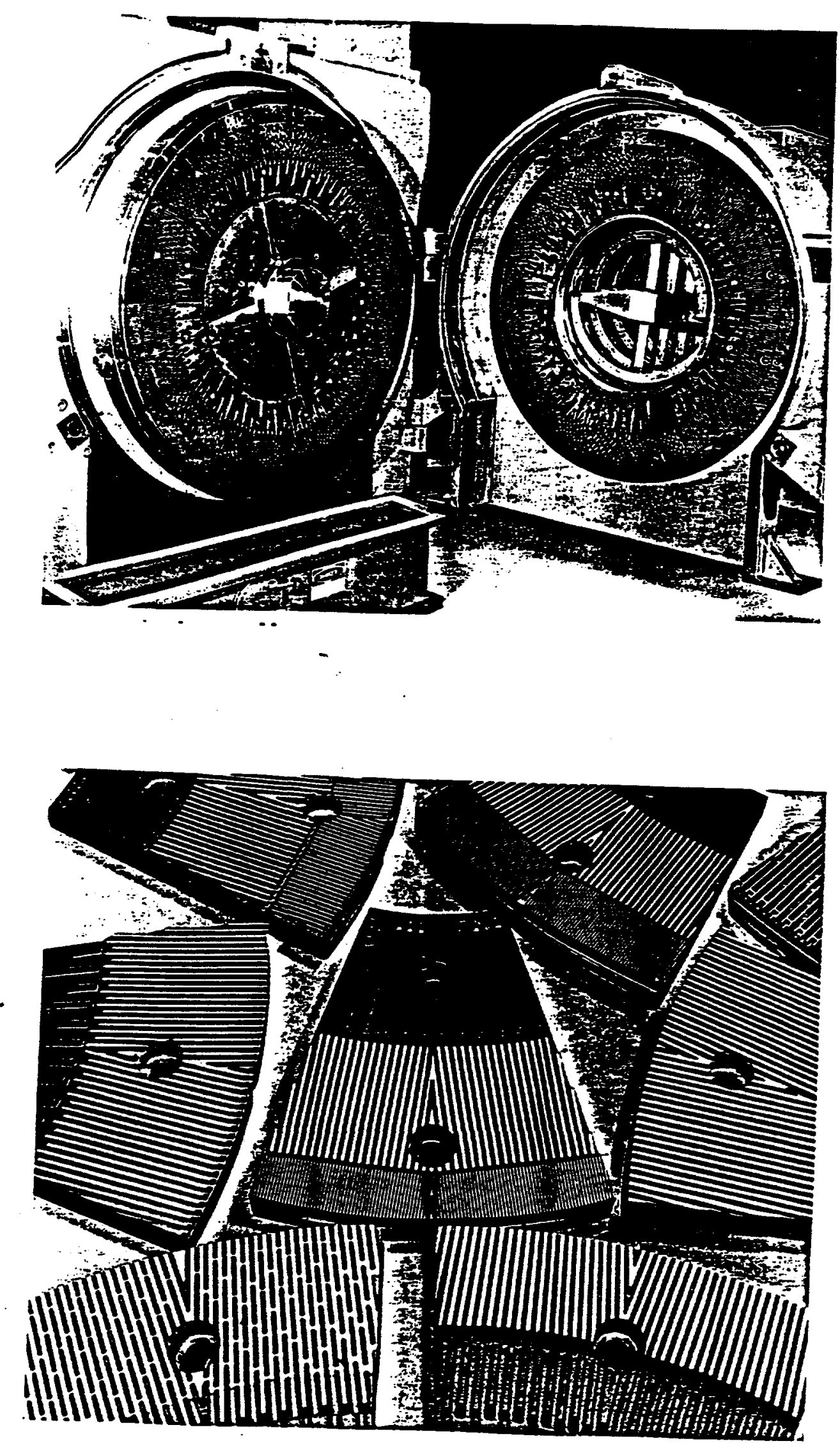

Figure 10 


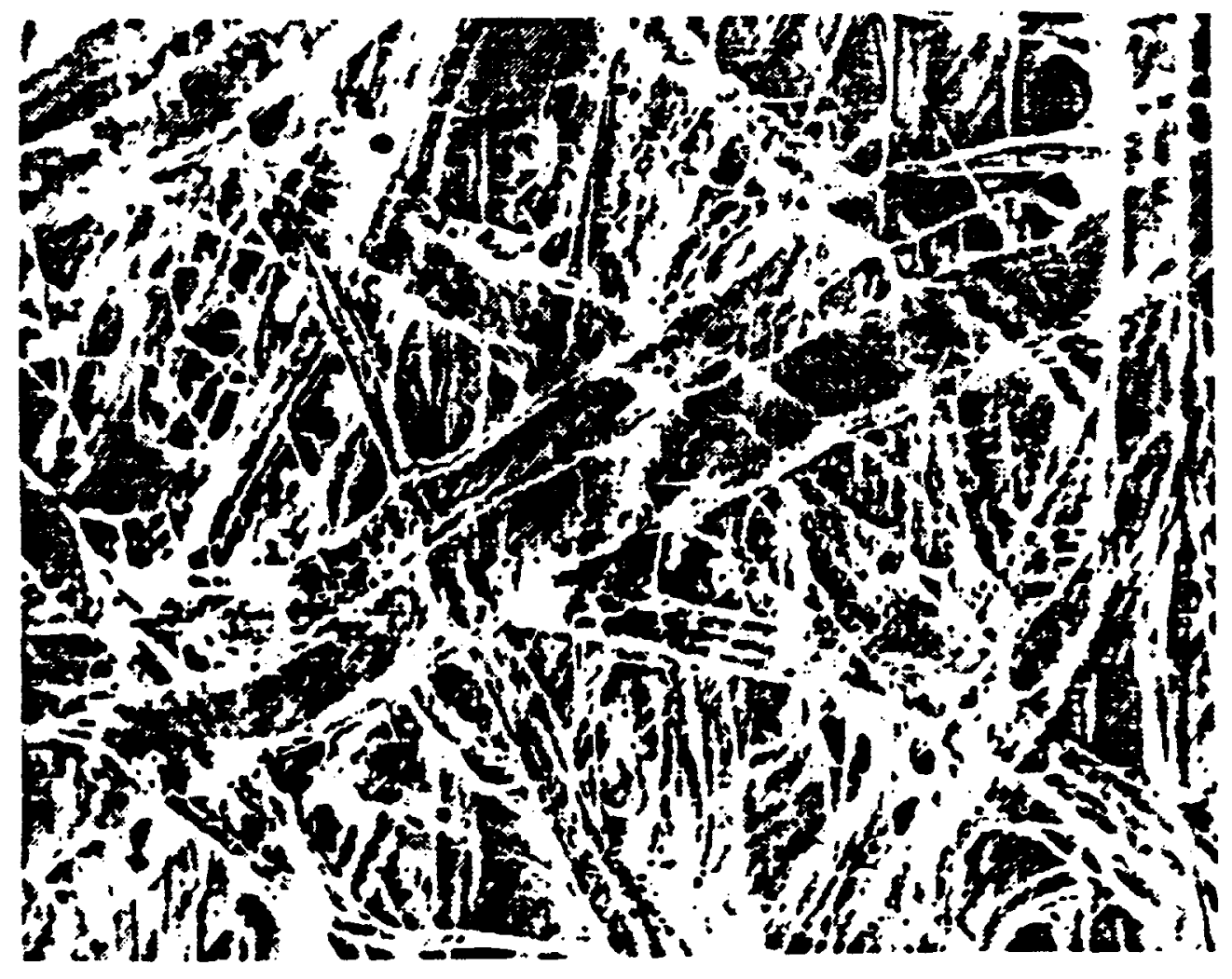

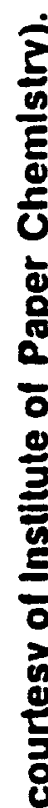

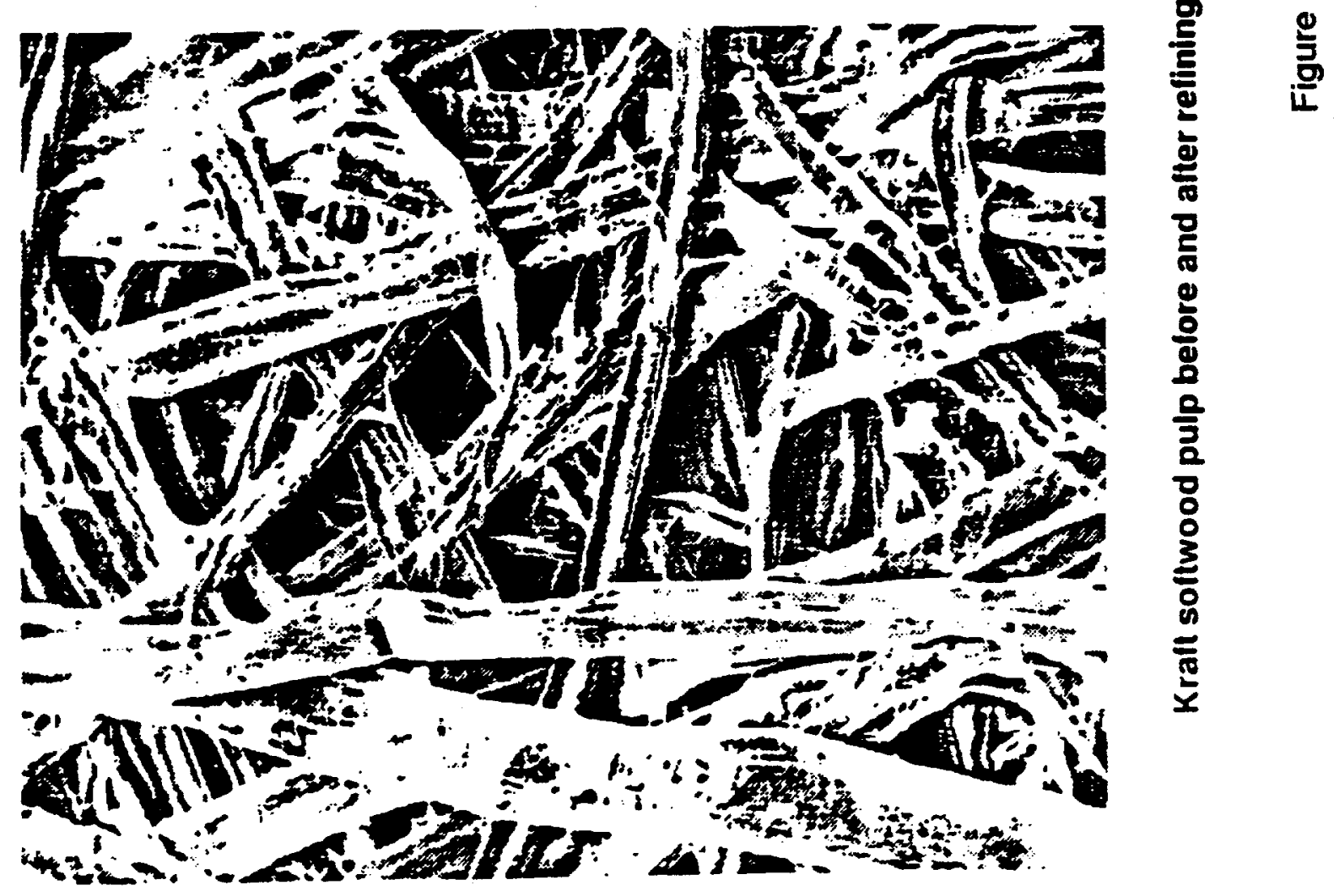




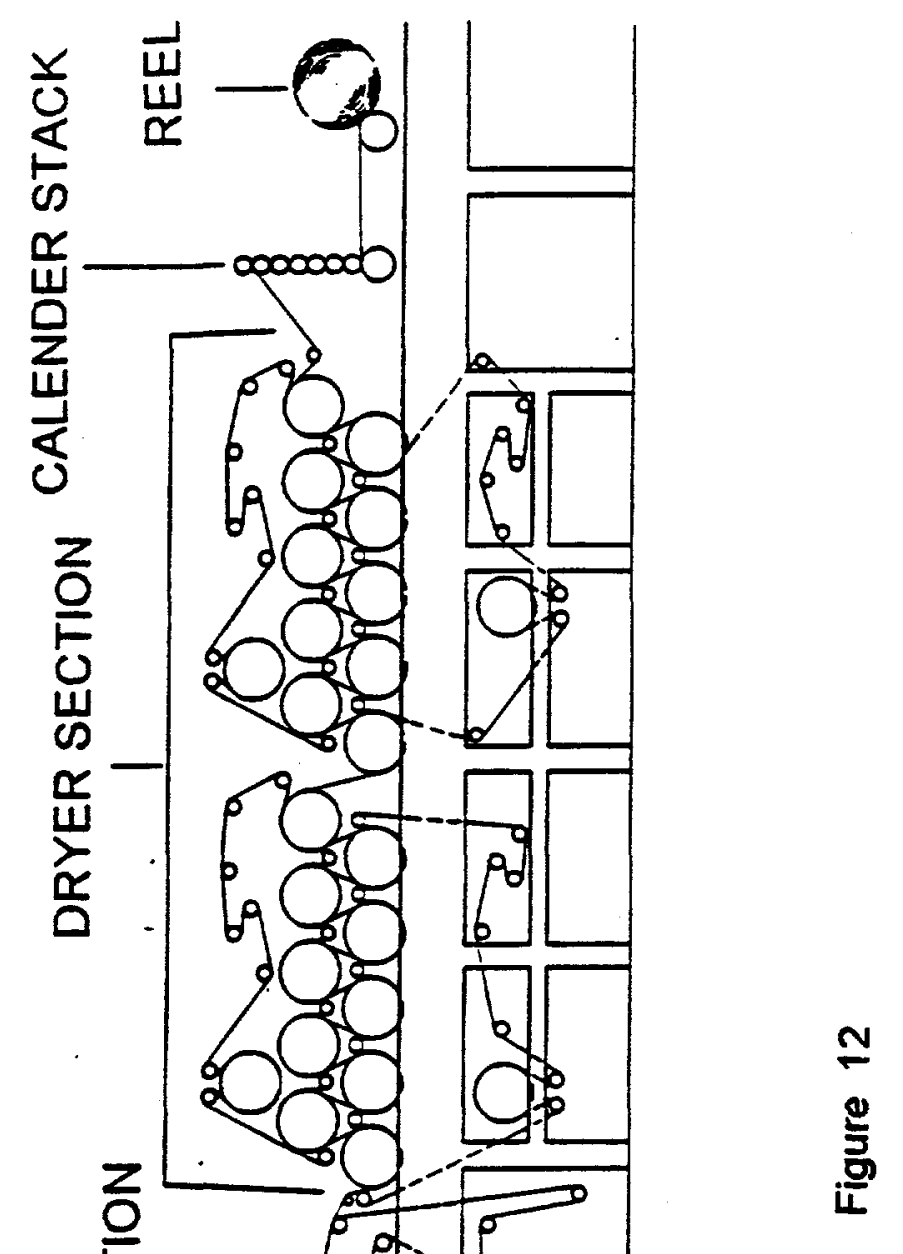




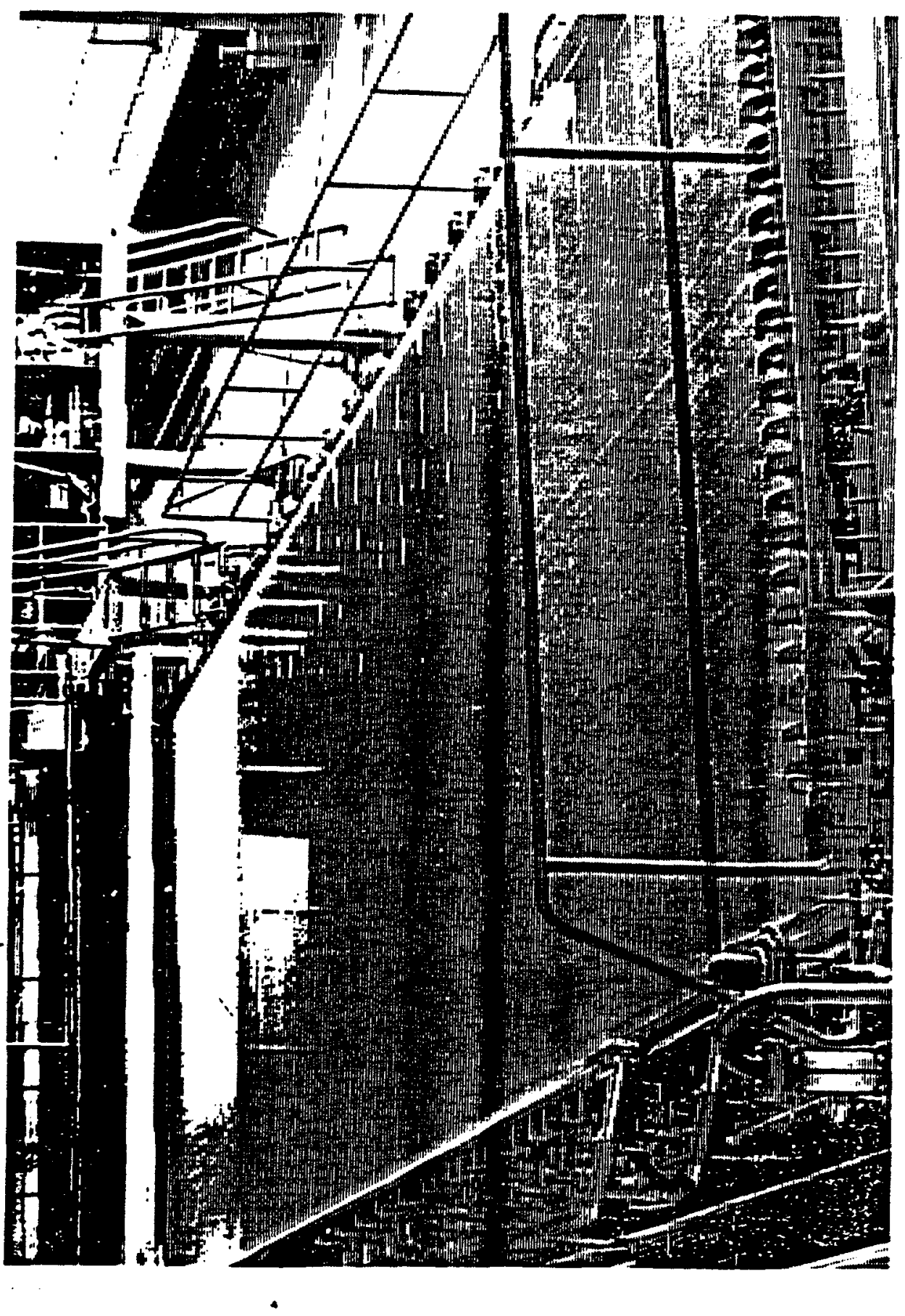

$\frac{m}{\frac{9}{5}}$ 


\section{PRINT METHODS}
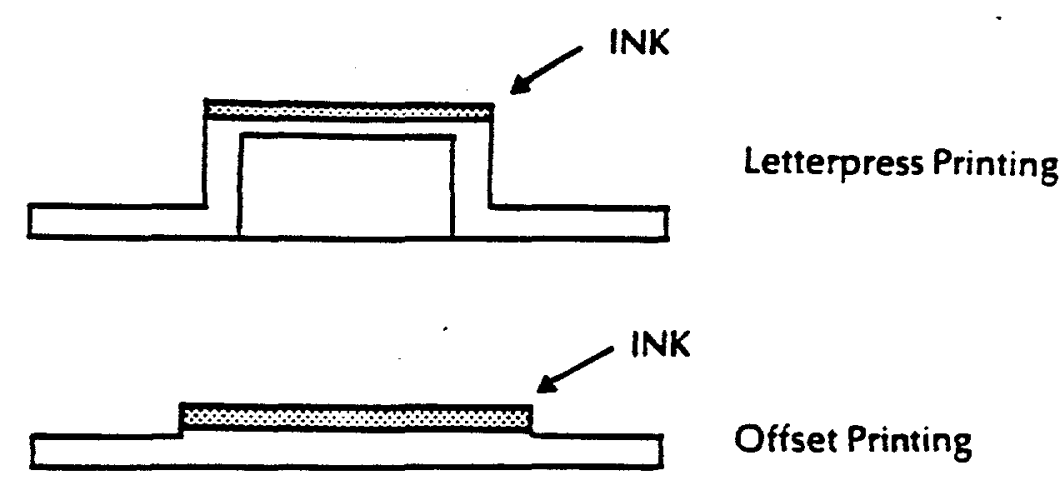

Offset Printing

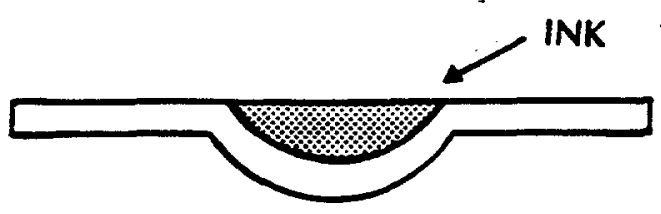

Gravure Printing

Figure 14 
TABLE 1

AF\&PA RESEARCH PRIORITIES
A. Sustainable Forest Management
B. Environmental Management
C. Energy Performance
D. Improved Capital Effectiveness
E. Recycling
F. Sensors and Controls

\section{TABLE 2}

\section{SENSORS and CONTROLS}

\section{PROCESS MEASUREMENTS AND CONTROLS}
A. Environmental-related Sensors
B. Process Related Sensors
C. Product Quality Sensors
D. Optimization/Total Mill Control
E. Expert Systems 
TABLE 3

\section{OTHER RESEARCH NEEDS \\ IN SENSORS AND PROCESS CONTROL}

\section{WOODLANDS AND WOODYARD}

Identification of wood species in chips

Measurement of chip acidity and degradation, for use as upset sensor and for determining buffering capacity of chips

\section{PULPING AND BLEACHING}

Improved sensor for Kappa number of pulp

Sensor for hemicellulose content and distribution

Sensor for $\mathrm{pH}$ that works in mill environment

Measurement of hydroxyl ion at high $\mathrm{pH}$

Sensor for reliable measurement of thick stock consistency

Sensors for fiber cell wall thickness, coarseness, fiber strength, and water retention

Measurement of residual sodium content in pulp, to be used for control of brown stock washers

Indicator for $\mathrm{BOD}, \mathrm{COD}$, and $\mathrm{AOX}$ in pulping and bleaching waste waters

Sensor for TOC

Sensor for oxalate

Sensors for alkalinity and sulfide

Sensor for $\mathrm{OH}$ free radical

Sensor for residual peroxide

Sensor for chlorine dioxide in gas phase

Sensor for chlorate concentration 
Measurement of dirt content in pulp

Measurement of pitch content

Detectors for foam

Techniques for avoiding explosions in chlorine dioxide generators and gas collection systems

Measurement of anthraquinone and polysulfide content during pulping

Sensor for odorous compounds

Sensor for refiner plate gap in mechanical pulping

\section{CHEMICAL RECOVERY AND POWER}

Measurement of black liquor solids at high solids levels $(\sim 70 \%)$

Sensor for improved measurement of white liquor conductivity

Sensor for $\mathrm{pH}$ and residual alkali in dregs and grit

Control strategy for black liquor evaporators

Sensor for in situ superheater tube surface temperature in recovery boilers

Sensors and control strategy for improved automatic sootblowing in recovery boilers

\section{STOCK PREPARATION}

Detection of pitch in furnish

Sensor for furnish turbidity, as indicator of filler fraction distinct from fiber fraction

Measurement of total amount and types of fillers in furnish

Sensor to detect shives and knots

Measurement of pulp color, for use in feedforward control of color

Measurement of fiber length, average and distribution

Sensor for distinguishing between broke fiber and virgin pulp fiber; this has potential for improving furnish $\mathrm{pH}$ control 


\section{RECYCLING}

Measurement of fiber cell wall degradation

Measurement of ash content in recycled furnish

Measurement of cationic demand

Measurement of fiber bonding potential and flexibility

Sensor for furnish color

Measurement of content of mechanical pulp

Detectors and controls for sorting of recycled papers

Measurement of fines content in recycled furnish

\section{PAPERMAKING}

Sensor and control strategy for dimensional stability

Measurement of water absorption of paper

Sensor for measuring fiber water retention and fiber saturation point

Sensor for formation that is effective at high basis weight, along with control methods for formation

Measurement and control of dryer pocket humidity

Control of color

Measurement and control of web tension

Measurement of surface orientation on two sides

Algorithms for integrated analysis of process and quality information

Smart system for process diagnostics

COATING, FINISHING, AND CONVERTING

Measurement of web tension

Measurement of roll moisture in printing/converting plant 
Measurement of dimensional stability

Measurement of printability (see list under Papermaking)

Sensors for rheological characteristics of coatings

Sensor for two-dimensional measurement of paper surface free energy and wettability

Sensor for detecting when free water disappears after coating application

WASTE TREATMENT AND ENVIRONMENTAL

Rapid measurement of BOD in effluent

GENERAL: MLLWIE, ENGINEERING, MAINTENANCE, OTHER

Techniques for predicting upsets in mill systems

Techniques for identifying and controlling inter-unit dynamics

Ways to reduce the total installed cost of process measurement and control systems

Development of improved control valves 


\section{PRIORITY SENSOR NEEDS}

1. Wood Chip Characteristics

2. Pulping Chemistry

3. Fiber Properties

4. Consistency

5. Colloidal Charge Measurement

6. $100 \%$ Web Inspection

7. Printability

\section{TABLE 5}

\section{KRAFT COOKING CHEMICALS}

Term

Dofinition

Units

(1) Total Alkali

Total of all "viable" sodium alkalj compounds, i.e. $\mathrm{NaOH}+$ $\mathrm{NaS}+\mathrm{Na}_{2} \mathrm{CO}_{3}+\mathrm{Na}_{2} \mathrm{SO}_{4}+\mathrm{Na}_{2} \mathrm{SO}_{2}+\mathrm{Na}_{2} \mathrm{SO}_{3}$ (Does not include $\mathrm{NaCl}$ )

(2) Total Titratable

Totat of $\mathrm{NaOH}+\mathrm{Na} \cdot \mathrm{S}+\mathrm{Na}_{2} \mathrm{CO}$

$\mathrm{g} / \mathrm{L}$ as $\mathrm{Na}_{2} \mathrm{O}$ Alkali (TTA)

(3) Active Alkali (AA)

Totat of $\mathrm{NaOH}+\mathrm{Na}_{2} \mathrm{~S}$

$\mathrm{g} / \mathrm{L}$ as $\mathrm{Na}_{2} \mathrm{O}$

(4) Effective Alkali (EA)

Total of $\mathrm{NaOH}+1 / 2 \mathrm{Nas}$

g/L as $\mathrm{Na}_{3} \mathrm{O}$

(5) Activity

Ratio of AA to TTA

expressed as \%

(6) Causticity

Ratio of $\mathrm{NaOH}$ to $\mathrm{NaOH}+\mathrm{Na}_{2} \mathrm{CO}$

$\%$ (on $\mathrm{Na}_{2} \mathrm{O}$ basis)

(7) Sulfidity

Fatio of Nass to AA (or to TTA) NB: The basis of sulfidity must be defined in each case.

\% (on $\mathrm{Na}_{2} \mathrm{O}$ basis)

TABLE 6

TABLE 7

FIBER PROPERTIES

Degree of Refining

Drainage Rate

Fiber Coarseness

Fiber Length

Cell Wall Thickness

Density

Flexibility

Conformability

Surface Oxidation

Surface Carboxyl Groups
Wet End Additives Applications

Control pH

Improve strength

Improve printing

Color.

Retention of Fines and Fillers

Sheet Formation

Drainage

Brightness

Pitch Control

Slime Control 


\section{AGENDA 2020 \\ SENSORS AND CONTROLS TASK GROUP \\ LIST OF PRIORITY NEEDS}




\section{A. Introduction}

There are two methods in use in the mill to make measurements of the paper web in order to assess its quality and effect some control. One is to take a sample strip across the width of the machine at each reel turn up. Reel turn up intervals are a function of grade and machine speed, but they will be in the order of 45 minutes. These strips are taken to a lab, divided further into samples across the width and these samples are then subjected to tests as required. There exist devices which can process the strip and make a battery of tests automatically. In any case, the results are not available in real time and certainly not useful for feedback control.

The present method for making on-line measurements of web properties is to mount a gauge on a traveling platform that moves back and forth across the web in the cross direction (CD) at right angles to the web travel in the machine direction (MD). The combined movement of the platform and the web results in a track on the web in a direction at an angle across the web. This angle is a function of the traversing speed and the web speed. Sensing areas for the various sensors are $1 / 4^{\prime \prime}$ to $2^{n}$ depending on type and year of installation. If the platform moves from one edge of the web to the other in 60 seconds and the web moves at 2500 feet per minute it will be seen that only a small fraction of the web is measured. The small measurement apertures are necessary so that streaks might be detected. Three or more sensors for different properties might be mounted on one platform. Basis weight (mass per unit area), moisture content, and caliper are commonly used sensors.

The first rule of paper quality is uniformity from point-to-point. The statistic used to judge this quality attribute is the standard deviation. The second rule, or requirement, is to meet some specification, on average. The statistic used is obviously the mean. These two statistics are determined for the sample values. They are used to calculate estimates of the population statistics, with all of the rules and caveats of statistics applied.

\section{B. Control}

In order to practice real-time control the on-machine measurements must be used. The measurements taken along the skewed path must be decomposed into two major components. One component represents the machine direction (MD) variability and the second represents the cross direction (CD) variability. This separation is necessary because the final control elements are different for each direction. 
The machine direction component, for control purposes, is represented by the average values for each scan. The cross direction component is obtained by creating average values for portions of the scan, for example every six inches of machine width (the data box), and averaging these values for two or more successive scans.

Basis weight, the mass of paper in a defined area, for example, 1000 square feet or 3000 square feet is a critical property of paper. The MD control of basis weight is accomplished by changing the flow of stock to the paper machine relative to the speed of the machine. This is done either by means of a stock flow valve or through speed adjustment of the pump which supplies this stock.

MD control is limited by the time interval between measurements and the dead time, that is the time from control action to response observed at the point of measurement. It should be noted that there is an inner control loop around the headbox of the machine which also affects basis weight.

The $\mathrm{CD}$ control of basis weight is accomplished by adjusting the opening at the lower front face of the headbox, the slice. Actuators attached to the slice, which is a beam that can be warped to some extent, cause this opening to increase or decrease in control zones which are typically four to six inches wide. The width of the control zones and the width of the data boxes mentioned above and their relative positions in the $C D$ must be coordinated.

There are some headboxes just coming into use in which CD control is accomplished by changing the consistency of the stock in control zones. These zones are less than six inches in width in some cases as small as 1 and $1 / 2$ inches.

Moisture content of paper affects its performance and therefore must be controlled. MD control of moisture is accomplished in most cases by adjusting steam flow to the dryer part of the paper machine. The rate of response in this case is relatively slow because of the inertia involved in changing the surface temperature of the dryer cans by changing the steam rate.

In cases where the machine is dryer limited, that is with the steam to the dryer section wide open the drying rate is limited by the machine speed, moisture control is through control of the machine speed.

There is coupling between the basis weight and moisture control which must be accounted for in the control algorithms. For example if the weight changes the drying response will change due to the change in mass on the dryer cans. 
$C D$ moisture is controlled by means of steam boxes, infra-red dryers, and water sprays. Each of these control devices is sectionalized so that actions specific to a $C D$ location can be taken. Steam boxes cause steam to impinge on the paper web. As steam is added in any section, water removal is enhanced in both the press section and dryer part of the machine. Infra -red dryers elevate the sheet temperature and enhance evaporation in the dryer part of the machine. Water sprays add water to the dry sections of the web

CD control of caliper is accomplished by heating or cooling sections of a roll in the calender stack. This changes the diameter of the roll and therefore the pressure applied to the web at that section. Coarse adjustments are made on specialized crown-control rolls by changing internal forces to adjust local roll diameter.

$C D$ control is limited by the width of the $C D$ control sections that can be accomplished by each type of actuator as well as by the ability to relate $C D$ measurements to specific regions of the actuator.

C. Basis weight, moisture, caliper. $(T 410, T 412, T 411)^{\star}$

There are three 'bread and butter' characteristics of the web that are generally measured depending on the grade. The first of these is basis weight which has the units of mass per unit of area. For some grades this is expressed as pounds per 1000 square feet, for others, as pounds per 3000 square feet. Some usage of grams per square meter exists. Basis weight generally includes moisture as well as fibers and other solid material. For control purposes, the moisture content must be subtracted from the total mass to identify specifically the dry mass per unit area.

The present method for making this measurement is through the use of beta radiation. Several different sources of radiation are used as well as several methods for detecting the unabsorbed fraction. Calibration of the sensor is required for each grade in order to account for the differing absorption coefficients of the particular constituents of each grade.

The most prevalent on-machine moisture measurement employs the use of near infra-red, particularly those frequencies which are highly absorbed by water molecules. Again calibration is required for each grade. There is some use of microwave energy for this measurement. Moisture is expressed as a per cent of the total web mass.

The third most common measurement is that of caliper in inches or millimeters. This measurement is made through the use of magnetic reluctance. 
An important feature of basis weight and moisture measurement is the ability to take the gauge off sheet on one side of the machine to insert a calibration sample in order to detect any changes in the measurement due to sensor drift, dirt build up or other factors. This automatic standardization is an important requirement that must be met for $100 \%$ measurement as well.

D. $100 \%$ measurement.

$100 \%$ measurement will be useful in improving existing automatic control in two ways. The first is the ability to separate the MD and $C D$ components uniquely so that control for each component won't be confounded by values from the other component. The second is that these measurements will be available at shorter time intervals. If the process can accommodate faster control this will reduce variability. For control purposes, the ability to obtain a set of measurements across the machine simultaneously, even if not $100 \%$, will be advantageous in that the separation of $M D$ and $C D$ components will be rigorous and available at shorter intervals than can be accomplished by moving a gauge platform across the web.

$100 \%$ measurement will also be useful in process diagnostics which is the second approach to control. With more data available it should be expected that some of the causes of variation which cannot be removed by feedback and/or feed forward can be tracked down and eliminated.

Economic benefits will be derived from improved product uniformity, which will enable end users (paper converters) to make their processes more efficient. In addition, $100 \%$ measurement will be helpful in resolving quality concerns with end users of the paper web. The end users have the advantage in that their processes do apply some force, coating, ink, etc. to $100 \%$ of the web. They see it all. In the case of printing, for example, they are concerned about areas as small as the dot in a gravure image. Increasing speeds of converting equipment have made customer systems more sensitive to paper variations. If the paper maker had this same capability then these discussions could be held on a more factual basis.

* See TAPPI TEST METHODS 


\section{E. Other measurements}

The priority order of the other measurements listed in this category will depend on who is asked because of the dependence on paper grades.

\section{Formation}

Formation is probably high on most lists as indicated by the fact that the Measurement Technology Committee (MTC) commissioned a study of commercially available instruments. Formation is a quality of the paper web which is judged by the uniformity of size and distribution of the fiber flocs, as well as variations in transparency. The method of measurement here is optical density where the sensor output is some measure of small scale variation. The major problem here is that there is no standard for this measurement. Control of formation is basically a papermaking 'art'. The papermaker may adjust refining, headbox consistency, chemical addition rates, furnish, forming section configuration, etc.

\section{Fiber orientation.}

Fiber orientation is receiving considerable interest now, and again the MTC has commissioned a study of commercially available sensors. The fibers exit the headbox in a jet at a velocity relative to the velocity of the forming wire that they fall on. At this point in the process the fibers represent about .3 to $1.5 \%$ of the furnish and they have some capability to move and orient themselves relative to the MD and $C D$ direction subject to hydraulic forces, gravity, and attraction forces exerted by neighboring fibers. They are also constrained to some extent by the formation of fiber networks that will become the flocs seen in the formation measurement. Fiber orientation is expressed in terms of the relationship between the number of fibers orientated in the machine direction as compared to the cross machine direction. The major axis of this orientation may be skewed slightly relative to the true MD/CD because of deviations from a true MD flow of the jet at different locations across the machine. Fiber orientation is also affected by how much the wet web is stretched as it moves down the web.

The main control of fiber orientation is through adjustment of the relative velocities of the jet and the wire, the jet to wire ratio. This will affect the average orientation. Changing the extent of wet straining is usually not a control option.

The deviations from true MD flow mentioned above may be attributed to the warping of the slice to achieve a flat basis weight profile. There is therefore an interaction between basis weight profiles and fiber orientation profiles. The new headboxes mentioned under $C D$ weight control are also claimed to be able to adjust fiber orientation. 
Fiber orientation requirements are based upon the end use of the product, but are of interest to products where out-of-plane deformation is important to performance.

\section{Stiffness and strength. (T494, T414, T818, T807)}

There are several attributes of paper strength which are of interest. They are;tensile, tear, ring crush, internal bond, and burst. Each of these is measured, destructively in the lab, using a TAPPI test method. An on-machine method cannot be destructive. Fortunately, it has been shown the stiffness measurement can be used to predict the failure end-point for several of these tests. Two onmachine devices are currently being evaluated to measure stiffness. One is a direct measurement of stiffness wherein the force required to deflect the web by a known amount is determined. The second method determines the velocity of ultrasonic waves in the web which have been shown to correlate well with stiffness. An advantage of the ultrasonic method is that the velocity in the direction of web thickness, the $Z$ direction can be measured. This measurement is important to a complete determination of the important strength properties of the web.

Strength will be a function of the furnish, pulping, refining, and papermaking conditions.

\section{Smoothness. (T479)}

Smoothness is a surface quality of the paper web. A smooth surface will be level or flat. In the lab, this property is typically measured by clamping the sample between two anvils. The lower anvil is a soft rubber pad. The upper hard circular anvil has a hole in the center. When suction is applied to the hole, air is drawn through the interface between the anvil surface and the paper surface. The time required to draw a fixed volume of air is determined. Because such air - leak tests are influenced by the porosity of the paper, the results are indicators of smoothness not a direct measurement. In recent years, optical and profilometry techniques have been introduced for lab measurement of smoothness but not for on-line use.

\section{Opacity. (T425)}

Opacity is an optical property of the paper web. In the lab it is measured by determining the amount of light reflected off the paper web under controlled conditions; i.e. the use of different backing materials when making the measurement. Control of opacity is usually through control of an inorganic additive such as $\mathrm{TiO}_{2}$ or clay. 


\section{Ash. (T413)}

Ash in paper is the inorganic material in the web from several sources. It is called ash because the TAPPI method involves igniting the web in a muffle furnace and measuring the resulting ash. Several methods are employed in on-machine gauges for detecting inorganics present. Common inorganic materials include clay, calcium carbonate, and titanium dioxide. An on-line measurement specific to each of these is necessary for control. Where both ash and opacity are controlled, the ash gauge may control the total organic addition while opacity is controlled by the ratio of types of organics employed.

\section{Coat weight}

A number of different types of coatings are added to paper webs for specific end uses. Clay coatings for printing grades and extruded plastic coatings for packaging grades are two examples. A typical method for measuring the coat weight is to measure separately the basis weight of the raw stock and the coated product and subtracting one from the other. This method suffers from the ability to identify specifically the same spot on the paper web when making the subtraction. Methods of measurement which would be specific to the coating material are available and are the desired method. Control of coat weight is obviously dependent upon the type of coating and the equipment used for its application.

\section{Color. (T1209 rp-87)}

Color is an optical measurement and many methods are available for its measurement. T1209 rp-87 describes briefly the four parts of color measurement. They are; a) the nature and source of the samples and the condition in which the sample are measured; b) the instrumental conditions of optical measurement , including instrument geometry and spectral properties of illuminant and light receptor, $c$ ) the standards used; d) the trichromatic color scales employed.

This document contains a comprehensive list of applicable documents referring to this complex measurement. Control of color can be relatively simple where shades of white are involved, to very complex where deep colors are involved. Several sensors for on-machine measurement are available.

\section{Gloss. (T480 and T653)}

Gloss is a measure of surface quality and shiny appearance. This measurement applies primarily to coated papers. The measurement employs a light source which is directed against the paper surface at a prescribed angle and the reflected light, at the same angle is measured. 
Visible defects are a whole range of discontinuities which are visible to the eye such as holes, spots, scratches, etc. A number of on-machine sensors are currently available, although the ability to measure very small defects over $100 \%$ of the paper surface in real-time has not been achieved.

\section{Surface free energy.}

Surface free energy is a measure of how wettable the paper surface is when ink or adhesive is applied. It is particularly important with coated paper and board products. Small-scale variations can be a problem leading to non-uniform print quality or incomplete adhesion.

II. Three dimensional mapping of fiber properties, real time, inside the digester.
A. Introduction.

Chemical pulping involves the delignification of wood by chemical means. In this process the lignin, which binds wood fibers to each other, is dissolved releasing individual fibers for further processing so that they may be used in making paper. The pulping process is carried out in large cylindrical vessels, called digesters. Wood is loaded into the digester in chip form, the cooking chemicals (liquor) are added, and, under heat and pressure, the chemicals penetrate the chips and preferentially dissolve the lignin.

After a suitable time the digester is emptied and the products of this reaction are removed for further processing. The product is washed to separate the spent chemicals from the fibers. The spent chemicals are routed through a recovery process and the fibers are routed to the stock preparation area for further processing prior to papermaking.

Two types of digesters are employed- batch and continuous. In a batch digester the chips and chemicals are loaded, the digester is sealed and heat is added either by adding steam directly to the digester or by circulating the liquor through external heat exchangers. 


\section{B. Control.}

The variables in this process are primarily chip size and quality, liquor strength, liquor-to-wood ratio and the time-temperature cycle. The control variables are time, active alkali, and temperature. A typical cooking cycle will be in the order of three hours. The digester is then emptied, called a digester blow, and a sample of the pulp is taken to determine the degree of delignification. A chemical titration test using potassium permanganate (T236) is used to determine the degree of delignification. The test value is known as the Kappa Number. The test value is used to judge whether the cooking conditions for the next batch should be altered. The operator will also have a measure of the liquor strength available for use in making this judgment.

Several sensors to measure delignification are available. One uses ultra-violet absorption to sense the degree of delignification and the output is expressed as Kappa Number. Some sample preparation is necessary before making this measurement. Available sensors are not considered adequate for high - yield softwood pulps, such as those used for linerboard.

As the delignification process proceeds, liquor strength diminishes as the chemicals react with the lignin. This change in strength can be monitored by measuring a property known as the Effective Alkali (EA). EA is the total of the $\mathrm{Na}$ $\mathrm{OH}$ and $1 / 2$ of the $\mathrm{Na}_{2} \mathrm{~S}$ present. This value is an indicator of the progress of the cook and is also used for control purposes.

A continuous digester bears some similarity to the batch digester. The chips are introduced at the top with the liquor, and the mass flows downward in "plug flow' passing through several zones each having a specific purpose.

The first zone at the top of the digester allows the chips to be impregnated at elevated temperature. In the next two zones, the upper and lower heating zones, the temperature is raised using liquor which is heated by recirculation through external heat exchangers. The next zone provides sufficient retention time for the pulping reactions to be completed. In the next zone the pulping reaction is stopped by displacement of the hot residual liquor with dilute wash liquor. At the bottom of the digester the pulp is removed through blow valves which accommodate the required pressure drop between the digester and atmosphere.

Control is accomplished through a complex algorithm which considers production rate, liquor temperatures, residence time, liquor strength, Kappa Number and residual alkali. Model reference control methods track horizontal slices of the mass of chips and liquor as they progress downward, predicting the final Kappa number for each slice. This predicted value is compared to the test value when available. 
The requirement here is the same as that in papermaking; i.e. maintain production rate and yield, minimize variation, and meet a predetermined average quality level. The problem encountered is that the wood chips are not all of the same size and/or quality, contact with the liquor is not uniform as liquor flow and temperature within the digester are not controlled in the scale of chip size. In the case of the continuous digester pulp flow downward in the digester may not be plug flow. All of this means that not every chip will be exposed to the same cooking environment, and those that are may respond differently to that environment.

\section{Fiber length and fiber flexibility.}

Two of the measurements listed in the meeting minutes under this heading do not appear to be relevant in this process- fiber length and fiber flexibility- as fibers do not appear as separate entities within the digester nor can these attributes be controlled here. These properties might better be listed under the heading of refining, which was not considered in this meeting.

\section{Liquor penetration and liquor strength}

Liquor penetration and liquor strength measurements across the diameter and up and down the height of the vessel would help to define the variability within the digester while the cook is proceeding and might be helpful if some control action was available to minimize variability. Batch digesters are approximately 50' high, 12 ' in diameter, with a shell thickness of $2^{\prime \prime}$, and produce 15 tons of pulp per blow.

\section{Hemicellulose content.}

Plant fibers contain cellulose, hemicellulose, lignin and extractives. The latter two components, lignin and extractives, are removed in the pulping process, while it is desirable to retain the two celluloses. The two celluloses taken together are known as holocellulose. They constitute the usable portion of the wood for papermaking and therefore contribute to the yield of the process- pounds of fiber per ton of wood.

Unfortunately the hemicelluloses are easily degraded and dissolved (compared to cellulose) by the chemical reactions which remove lignin. Knowing the hemicellulose content would make it possible to optimize the yield to KAPPA relationship. Hemi cellulose content should be correlated to liquor penetration and liquor strength, so the potential benefit is much the same as mentioned above.

\section{Carbohydrates.}

(As in the case of surface free energy I would appreciate help from the Committee in describing what should be measured and how the measurement will be useful. 
As noted above chip characteristics have a considerable influence on the results of chemical pulping. The same can be said for TMP and CTMP refining

A. Thickness, moisture, density.

Variations in thickness, moisture, and density will lead to variations in liquor penetration in chemical pulping and variations in fiber separation in mechanical pulping. Since these processes treat chips in bulk, measuring these properties ahead of the digester, or refiner, will provide little benefit to reducing small scale variability. If the property variation is long term relative to the process retention time then some feed forward control might be possible.

\section{Thickness and length.}

Measuring thickness at the output of the chipper might provide some feed back control possibility. It might also be possible to sort by chip thickness so that chips of a given size could be sent to the pulp mill over a long enough period, again relative to the retention time, so that short term variability is reduced. This, of course, would require some bin storage capability by size. Some sorting by means of screens is used to separate over size chips for further size reduction and fines and/or sawdust for disposal or use as fuel.

Thickness of 'good' chips will range from 2 to $5 \mathrm{~mm}$. and length from 10 to 30 $\mathrm{mm}$.

2. Moisture. (T258)

Where chips are subjected to washing ahead of pulping measuring chip moisture might have some value in feedback control. For chemical pulping, an integrated measurement of chip moisture would be helpful in adjusting the liquor-to-wood ratio in chemical pulping and the dilution water flow rate in TMP refining..

\section{Density. (T258)}

Density measurement is important to chemical pulping because the chips are introduced into the digester on a volumetric basis. As in the case of moisture, density measurement would be used in adjusting the liquor-to-wood ratio. There are two measures of density. Wood density refers to the density of specific chips, and bulk density refers to the density of groups of chips as for example in the chip meter feed to a digester or the screw feeder to a TMP refiner. 
B. Bark content.

Measurement of bark content would be a tool for assessing the quality of incoming chips and would be used to identify those chip sources where debarking is inadequate. Several processes have been developed for removing bark from chips.

C. Species distribution.

Species control is best handled at the wood source. It should be noted that in Scandinavia, where they 'campaign' digesters alternately between hard wood and softwood, on-line fiber length measurements are used to track the front, hardwood/softwood, through the process so that appropriate adjustments can be made in unit processes down stream of the digesters.

IV. Recovery boiler.

A. Stack emission monitor.

For energy efficiency and environmental control it would be useful to monitor stack gases in a recovery boiler. DOE has a current project with Advanced Fuel Research that has produced a Fourier Transform - Infra Red sensor for this purpose. The results of field trials should be reviewed before new work is started.

B. Boiler tube monitoring.

The spent cooking liquor from the chemical pulping process is burned in a recovery boiler as the first step in recycling the chemicals. Combustion of the organic components takes place in a boiler lined with tubes carnying water to be heated and converted to steam. The in-organic components of the black liquor fall to the bed of the furnace and form a molten smelt which is withdrawn for recycling.

If the water tubes develop a leak which allows water to impinge on this smelt bed, an explosive mixture is created. For this reason it is important to monitor the integrity of these tubes, and/or to detect a leak early enough to allow the boiler to be shut down before a catastrophe occurs. Tube thickness, embrittlement, pitting and corrosion are all factors which may be used to predict the possibility of a tube leak occurring. It would be ideal to be able to detect these properties while the boiler is running.

A computer based simulation model, based on expert systems concepts, is currently being evaluated for early detection of tube leaks. 
C. Smelt bed monitoring.

In a conversation with our colleague Sam Suh following the meeting, he suggested that monitoring the properties of the smelt and smelt bed would be a useful adjunct to recovery boiler control. Please let me know if you wish to add this to the wish list.

\section{Recycled fiber quality.}

The paper industry is currently using a large quantity of recycled fibers. In aggregate $40 \%$ of paper production consists of recycled fibers. This reduces the need to cut virgin wood and also reduces the load on land fills. Recycled fibers may be of lower quality than virgin fibers for a number of reasons and they will be of varying quality depending on their prior history. Contaminants are another problem.

In order to use the maximum quantity of these fibers, in conjunction with virgin fibers, it would be desirable to measure their important quality attributes at the point of use.

Fibers tend to become shortened through processing, their cell walls degrade, and their bonding potential is altered. In addition contaminants may become adhered and both the ash content and the cationic demand may vary.

A. Fiber length.(T271, T233)

Fiber length was mentioned above in the digester section. A currently available method which has achieved wide use employs an optical method which can be used on samples taken from the process stream. In this method the sample is diluted so that individual fibers can be directed to flow through a capillary tube past a pair of optical detectors. The time between interrupts of the illuminating beam is used to determine a fiber length.

B. Cell wall degradation.

The cell wall of a paper fiber is a complex structure which is altered to some extent in the pulping and refining processes. Pressing and drying on the paper machine may further alter this structure, as will end use in printing, bag making and box making. This degradation may effect the fibers ability to meet the requirements of the new grade for which it is intended. 


\section{Contaminants adhered to the fiber.}

Recycled fibers pass through a reclaim process which is intended to remove contaminants that may be adhered to the fiber surface. Deinking is one such process. It is obvious that determining the quality of these contaminant removal processes would be highly beneficial.

\section{Ash content.}

Ash content was included under $100 \%$ web measurement. In this case it would be useful to make this determination on recycled materials.

\section{E. Cationic demand.}

Paper chemicals are a major cost component of many paper grades. They are frequently used to improve retention and formation. Formation was discussed briefly under web measurement. Retention refers to the ability to keep the fines constituent of the paper making furnish in the sheet as it passes over the fourdrinier section of the machine.

These chemicals are cationic in nature. Anionic 'trash' materials in the furnish compete with fibers and fillers for these expensive chemicals. Therefore it is necessary to know what the cationic demand of the recycled material will be. Zeta potential and streaming current potential are two methods presently employed. A number of sensors employing these techniques are now available. Their usefulness, especially in highly conductive systems, is a matter of some debate.

\section{F. Bonding potential. (T541)}

A paper web develops strength in part due to the bonding of fibers where they cross. A destructive method exists for measuring the internal bond strength of a paper sample consisting of a large number of fibers. Several laboratory devices have been reported in the literature which claim to be able to measure the flexibility of individual fibers one at a time. Flexibility might be correlated to bond strength but it will not be the only factor. The Z-direction ultrasonic velocity sensor under development and evaluation by IPST is a non-destructive means for evaluating bond strength after the web has been formed.

\section{Automated sorting of recycled raw material.}

Some effort is made to sort recycled raw material at its source. Newsprint collection and corrugating container collection at grocery stores are two examples. in general these are not reliable methods for sorting based on the needs of the papermaking process. 


\section{A. Non-cellulose components.}

Plastic is a particularly troublesome contaminant as it tends to adhere to the wire in the fourdrinier section and rolls in the press and drying section. The term 'stickies' is aptly used to describe this contaminant.

\section{B. Color}

Deep shades of color are a particular problem in white grades. High print coverage grades, as for example four color "photographs, also degrade final product quality.

\section{Groundwood.}

One mechanical pulping process is known as groundwood because fibers are separated from each other by use of a large emery stone. This fiber source has advantage in some grades and is a low cost fiber. It also is a low strength fiber and therefore not desirable in grades requiring strength.

VII. Three D characterization of tree structure related to end use properties

\section{A. Field deployable.}

I would hope that, upon reflection the Committee would see the wisdom of passing this one along to the Sustainable Forest Management group before asking our friends at the National Labs to give consideration to it.

\section{B. Best opening face.}

In this instance we have a national lab (Forest Products Lab) who have done work on this topic.

\section{Fiber characterization.}

Fibers are the fundamental building blocks in a paper web and their individual characteristics contribute to the quality of the paper made from them. We do little to determine the characteristics of individual fibers such as fiber flexibility, S2 angle, cell wall thickness, and cell wall integrity. It is difficult to imagine how this could be done in a paper mill but it would ,of course, be useful to have reliable methods that might be used in a research environment. This is a forward looking requirement in that present research efforts may yield benefits in the longer term.

Characteristics of groups of fibers are of interest. These characteristics can be expressed as distributions. Fiber length and coarseness are two such characteristics. 
A. Fiber flexibility.

If one looks at a photo micrograph of a paper sheet the advantage of fiber flexibility is clearly seen as the fibers are able to conform to each other at fiber crossings. several laboratory devices have been reported which claim to have value in this connection

B. S2 Fibril angle.

A wood fiber has four individually distinguishable walls beginning with an outer primary wall , followed by three successive secondary walls. The secondary walls are made up of fibrils with different alignments. The secondary wall forms the main body of the fiber and is 2 to 10 micrometers thick.

C. Cell wall integrity.

During refining the fiber structure must be altered so that the fiber can become flexible. The degree of disruption of the cell wall as result would be of interest.

D. Fiber length. (T271)

See Recycled Fiber quality. Fiber lengths will range from 1.8 to $6.1 \mathrm{~mm}$ and diameters from 20 to 65 micrometers.

E. Coarseness. (T234,T271)

Coarseness is expressed as weight per unit length, expressed as milligrams per $100 \mathrm{~m}$ (decigrams per $10 \mathrm{~km}$ ). The unit is called a decigrex and is analogous to denier of textile fibers. 